\title{
How Pro-social Framing Affects the Success of Crowdfunding Projects: The Role of Emphasis and Information Crowdedness
}

\author{
Daniela Defazio' $^{1}$ (1) $\cdot$ Chiara Franzoni $^{2} \cdot$ Cristina Rossi-Lamastra $^{2}$
}

Received: 12 April 2019 / Accepted: 7 January 2020 / Published online: 23 January 2020

(c) The Author(s) 2020

\begin{abstract}
Crowdfunding is regarded a financing mechanism that could improve the funding opportunities of businesses with a pro-social orientation. Indeed, it is assumed that on digital platforms, citizens are inclined to provide more support to projects with a social benefit than to those without such an orientation, with significant ethical implications for the common good. Yet, extant empirical evidence regarding such a claim is still inconclusive. To advance this discussion, the present paper analyzes the conditions that influence crowd support for projects displaying a pro-social orientation on a reward-based crowdfunding platform. To build our hypotheses, we adopt the lens of framing theory, and we relate it to the digital context. Beginning from the premise that, on crowdfunding platforms, information about projects has a hierarchical structure, we argue that a project's success crucially depends on how much its proponent emphasizes the pro-social cues within this structure. Moreover, we propose that because pro-social cues demarcate a project over others, the effectiveness of pro-social framing is enhanced when the number of projects on the platform, i.e., its crowdedness, increases. Logit estimates on 8631 Kickstarter projects indicate that pro-social framing is positively associated with success as we expected, yet only when it is moderately emphasized. Further, we find that crowdedness on the platform positively moderates the effect of pro-social orientation on success.
\end{abstract}

Keywords Pro-social framing $\cdot$ Crowdfunding $\cdot$ Digital platforms $\cdot$ Emphasis $\cdot$ Crowdedness

\section{Introduction}

There is a general interest in studies of business ethics concerning whether the emergence of crowdfunding-a new form of fundraising in which citizens provide financing to projects directly through the Internet-could improve the ethical standards of entrepreneurial finance (Fassin and Drover 2017; Johnson 2015). The expectations that crowdfunding could provide a step towards a more ethical entrepreneurial finance are based on two reasons. First, crowdfunding enables direct contact between entrepreneurs and citizens, and thus it by-passes the traditional providers of

Daniela Defazio

d.defazio@bath.ac.uk

Chiara Franzoni

chiara.franzoni@polimi.it

Cristina Rossi-Lamastra

cristina1.rossi@polimi.it

1 School of Management, University of Bath, Bath, UK

2 School of Management, Politecnico di Milano, Milan, Italy finance, such as banks and venture capitalists, whose investment decisions are usually profit-oriented with little consideration for the social or ethical goals that entrepreneurs might have (Drover et al. 2014; Johnson 2015). While the traditional financial sector is seen as alienating investors from their investments, crowdfunding is greeted as an opportunity for investors to engage directly with entrepreneurial projects and to actively select investment goals and opportunities (Johnson 2015, p. 61). Second, in many cases, entrepreneurs resort to crowdfunding to seek money for starting their first venture and transform their ideas into products to be sold on the market (Colombo et al. 2015; Mollick 2014). In such a nascent stage, as the company, its product, and its marketing choices often coincide, backers might have the impression that they can assess the goals, the values, and the overall ideology associated with entrepreneurial ideas, and can make decisions that are meaningful and influential (André et al. 2017; Calic and Mosakowski 2016). This case is different from that of large, multi-product, multi-market corporations in which the public is allowed only modest levels of influence on corporate actions and where there are often multiple overlapping messages that relate to the ethical 
orientation of the brand, the product and the marketing campaign (Crane 2001).

Despite this burgeoning interest in the pro-social orientation of crowdfunding, empirical evidence on the topic is still limited and rather inconclusive. Studies conducted on microlending platforms that focus primarily on pro-social impact indicate that a greater emphasis on pro-social orientation is associated with faster fundraising (Allison et al. 2015; Moss et al. 2018). However, little is known about how the display of pro-social goals helps to raise resources in traditional for-profit sectors, where there is usually a need to balance the pro-social aspects with the personal self-interest of the funder (Van de Ven et al. 2007). Addressing this issue is one aim of this work. To this end, reward-based crowdfunding platforms represent an interesting testbed.

In particular, the paper offers four main contributions: it advances the literature on the role of pro-social orientation for mobilizing resources in a for-profit context; it contributes to the literature on crowdfunding; it expands the theory of framing and it advances the methodology that analyzes web-based messages in social studies. Our results also help explain some of the contrasting results of prior studies and depict a more nuanced picture of the role of pro-social orientation in reward-based crowdfunding.

Specifically, we identify a project as pro-socially oriented when it displays awareness and care for others, the society and the environment; and when it champions the values of fairness and inclusiveness (Brickson 2007; Nilsson 2008; Secchi 2009). We conceptualize the effects of pro-social orientation on crowdfunding projects' success by drawing on the framing literature (Benford and Snow 2000; Goffman 1974; Rhee and Fiss 2014), which posits that framing-i.e., the selection, packaging and organization of information (Giorgi and Weber 2015)—serves to attract the attention of an audience because it demarcates and sets apart significant information from the background, and because it motivates individuals to act in support of a particular goal. Further, we apply framing theory to the digital context, where information is organized hierarchically in hypertexts (McKnight et al. 1991) and can be overly abundant (Broniarczyk and Griffin 2014; Hansen and Haas 2001). This enables us to elaborate hypotheses on the effectiveness of pro-social framing in digital contexts, suggesting the conditions under which pro-social framing helps to achieve success, with significant consequences for the study of business ethics and its focus on pro-social routes to market success.

In line with prior research, we identify pro-social framing by linguistic cues (Shen 2004) ${ }^{1}$ contained in titles, blurbs

\footnotetext{
${ }^{1}$ According to Druckman et al. (2010), as long as it constitutes information that individuals use to simplify their decision-making process, a frame could be seen as an example of a cue.
}

(i.e., a short promotional phrase), and descriptions of crowdfunding projects. We derive scores of pro-social framing by means of Computer-Aided Text Analysis (CATA) for a sample of 8631 projects hosted by the reward-based platform Kickstarter.com and run logit estimations to test our hypotheses, finding overall support. Our results show that while a limited emphasis on pro-social framing positively relates to success, a strong emphasis (too many or too prominent prosocial cues) is negatively associated with success. Furthermore, pro-social framing can be more helpful when on the platform there are many projects that compete for attention.

The remainder of the paper proceeds as follows. The next section reviews the crowdfunding literature on the effect of pro-social orientation on crowdfunding success; it introduces the theoretical background and develops the research hypotheses. It is followed by a description of the data and methodology used in the empirical analysis. Subsequently, we present the results of the empirical analysis and a set of robustness checks. Then, the final section discusses the results and concludes the paper by highlighting contributions, limitations, and directions for future research.

\section{Literature Review and Research Hypotheses}

\section{Pro-Social Orientation and Crowdfunding Success}

Scholars investigating the determinants of crowdfunding success, and specifically the role of project orientation, have provided a variety of explanations of how a pro-social orientation influences backers' support. Allison et al. (2015) propose that the linguistic cues emphasizing the pro-social nature of a business venture act upon individuals' intrinsic motivations to help others. Their results show a positive effect of such cues on the amount of funding collected on the platform Kiva.org. Moss et al. (2018) further add to this study by investigating whether projects displaying a hybrid orientation, i.e., include linguistic cues to both pro-social and economic values, are preferred to projects that have a narrower focus on just one orientation. The authors show that, on micro-lending platforms (Kiva.org), a greater prosocial orientation tends to accrue more backers' support, allowing a project to stand out and garner resources faster than less pro-social projects.

Calic and Mosakowski (2016) suggest that support in reward-based crowdfunding is explained by the loose affiliation of participants with a community that values sustainability. Their study finds that projects displaying a sustainability and/or an altruistic orientation are more likely to elicit crowd support in technology-oriented projects on a rewardbased platform. However, Hörisch (2015) offers divergent results, documenting that there is no positive link between environmental orientation and success. Instead, his findings 
hint at a negative relationship, although, it is worth noting that the empirical approach that he uses to identify projects having an environmental orientation differs from the one used by Allison et al. (2015) and by Calic and Mosakowski (2016). In fact, the author does not resort to a linguistic analysis of the project description but instead relies on the "environmental" tags assigned to the project by the platform. He explains his results by arguing that, according to rational choice theory, rational individuals in a market context are primarily concerned about their self-interest. Kim et al. (2016) find that campaigns for social causes were less likely to succeed, but, if successful, they raise more money than others do. André et al. (2017) distinguish pledges depending on whether they are equal to rewards (i.e., transactions), higher than rewards (i.e., reciprocal giving), or simply no reward (i.e., non-reciprocal giving). Their findings, based on data from the platform Ulule.fr, show that the more pledges are based on non-reciprocal giving, the less successful the project is. However, the proportion of reciprocal giving pledges has a positive effect on success and projects that rely only on transactions are significantly less successful than the other projects. Finally, Allison et al. (2017) adopt a theory of persuasion to explain the effect of different types of cues (i.e., central and peripheral) on the motivation to support a project in reward-based crowdfunding. Among the factors identified as peripheral cues (i.e., not related to the central route to persuasion, which encompasses information on the functionality of the product or the background of the project proposer), the authors investigate the effect of cues to group identity. They argue the backers might appreciate such cues as they suggest an opportunity to help others and feel part of a community; in this sense, such cues are expected to elicit backers' support by engendering affective commitment. However, the authors find inconclusive results on the effect of these pro-social peripheral cues on the motivation to invest in crowdfunding projects.

Two main gaps emerge from this brief literature review. First, an important element to consider when comparing prior results is the specific context of the analysis. ${ }^{2}$ Some platforms, like Kiva.org, have a clear pro-social mission and the funders do not serve their self-interest when they choose a project because they do not earn any interest. The results from studies based on platforms like Kiva.com consistently show that pro-social motives are a plus. On the other side, results related to reward-based platforms, like Kickstarter. com, are mixed. This second kind of platforms care about the social impact of projects, but their primary mission is not typically pro-social. Indeed, the backers on Kickstarter. com can be motivated by self-interest when they choose

\footnotetext{
$\overline{2}$ See Hemer (2011) for a discussion on the different crowdfunding models.
}

among projects because many rewards are products with a specific functional use (Allison et al. 2015, 2017). Moreover, the debate on pro-social motives has greater interest in contexts where there is a need to balance self-interest and pro-social motives (Van de Ven et al. 2007). Entrepreneurship theories that seek to explain entrepreneurs' ability to mobilize resources have traditionally made a distinction between social and for-profit enterprises, considering them as two different phenomena. The underlying assumption is that entrepreneurs adopt either a social or a for-profit orientation, but not both at the same time (Van de Ven et al. 2007). In fact, traditional theories of entrepreneurship are based on economic rationality, that is individuals exclusively pursue their self-interest, and this is seen as incompatible with the simultaneous pursuit of social interest. In particular, the display of social goals in for-profit-oriented enterprises has been seen as detrimental for resource mobilization as it conflicts with profit goals and investors' self-interest (Austin et al. 2006). Yet, this argument reflects the view that institutional investors are the main providers of funds, and they are only interested in pursuing self-interest. In contrast, an increasing amount of evidence suggests that entrepreneurs who can blend pro-social motives and self-interest are better able to engage others and gain more resources (Van de Ven et al. 2007). However, there is little empirical research investigating how pro-social and self-interested logics can be combined to provide an advantage in mobilizing resources. Our study addresses this gap by looking at technology and design projects in Kickstarter, a context where self-interest and functional product values are important.

Second, although crowdfunding is a digital environment, the extant literature has devoted surprisingly little attention to the way in which the pro-social message is conveyed in such contexts. Studies of communication in digital environments have highlighted that information is provided in hierarchical structures (McKnight et al. 1991) and is typically overly abundant (Broniarczyk and Griffin 2014; Hansen and Haas 2001), which makes it important to analyze the framing of information.

Moving from these premises, in the following, we first review the literature on framing and on the effects of prosocial framing on organizational performance; then, we take inspiration from this literature to develop our research hypotheses.

\section{Framing Theory and Pro-Social Framing}

Framing is the selection, packaging and organization of information about an object (e.g., a product, a service, a problem, a cause, or a situation) that enables an audience to interpret and make sense of it (Fiss and Hirsch 2005; Giorgi and Weber 2015). At the same time, framing evokes "extra" information about the object and facilitates the setting of 
the audience's expectations (Cornelissen and Werner 2014). Framing is known to affect individuals' decisions in two ways. First, it helps in demarcating one object from the others by acting as a marker, i.e., an attribute that distinguishes the object over other (similar) ones and makes it stand out (see Giorgi and Weber 2015). For instance, by framing a product as "green"-i.e., providing environmental benefits or reducing environmental costs-marketers evoke characteristics associated with environmental-friendliness (e.g., the commitment to preserve the environment for future generations or the respect for natural habitats). In so doing, they demarcate the product over other non-environmentally oriented products. Such demarcation is meant to attract the support of environmentally concerned individuals. Accordingly, by demarcating a product over others, a framing can facilitate individuals' selection process among a choice-set.

Second, framing is also presented as a powerful tool for motivating and eliciting appreciation and support from an audience. Such a role has been highlighted in a variety of contexts, including political rallies (Chong and Druckman 2007b), social movements (Benford and Snow 2000), and financial analysts' reports (Giorgi and Weber 2015). In this respect, a specific framing is seen as an effective tool in attracting an audience not only because it enables selection, but also because it motivates individuals to act in support of a specific goal.

Pro-social framing has received increasing attention in the economic and managerial literature, where it is often associated with positive outcomes. In particular, scholars provide empirical evidence that customers and employees positively value such framing, which is thus conducive to superior firms' performance (Bhattacharya et al. 2009; Marin and Ruiz 2007; Olsen et al. 2014; Sen and Bhattacharya 2001). For instance, firms that introduce "green products" benefit from a greater improvement in the attitudes of their consumers towards their brand compared to those that introduce similar "non-green products" (Olsen et al. 2014; Reinhardt 1998, p. 46). Investors are also increasingly reported to appreciate pro-social orientation (Rodgers et al. 2013). Financial analysts' attitude towards pro-social orientation has progressively changed, turning from negative investment recommendations in the early 1990s to optimistic recommendations in recent years (Ioannou and Serafeim 2015).

Drawing from the literature above, in the following section, we develop our hypotheses on the factors that shape

\footnotetext{
${ }^{3}$ However, Eckhardt et al. (2010) noted that green products or "ethical" products (e.g., products that are certified as Child Labor Free), although appreciated, do not necessarily translate into larger market shares.
}

the effectiveness of pro-social framing in the crowdfunding context.

\section{Research Hypotheses}

\section{Emphasis and the Effectiveness of Pro-Social Framing on Crowdfunding Success}

How a frame is conveyed effectively to an audience by means of written texts is an issue that has received attention from framing scholars (Giorgi and Weber 2015; Olsen et al. 2014; Rhee and Fiss 2014; Shen 2004). These studies highlight that cues that refers to concepts central to a frame make the frame accessible to an audience and activate judgement and action.

However, a frame can be conveyed in different ways within a text. Specifically, as to crowdfunding projects, some entrepreneurs might put a strong emphasis ${ }^{4}$ on a specific frame by providing a large number of cues related to it while others might give less emphasis. The issue of how much emphasis should be placed on a specific frame to attract an audience's attention and motivate the audience to act upon it is still underdeveloped in the framing literature. In particular, Hertog and McLeod (2001) point out that a frame does not need to be emphasized to be effective, and "one or two references might be enough to set the frame for a large amount of context" (p. 152). Moreover, extant research suggests that over-emphasizing a frame may reduce its effectiveness. There are two main reasons for this. First, too much emphasis may hamper the credibility of framing, which is one of the key determinants of its effectiveness (Levin et al. 1998). In line with this view, Parhankangas and Ehrlich (2014) show that startups that promote themselves through an overly positive language are less likely to attract business angels' support. Second, as noted by Burke (1984, p.28), a "frame centers the attention upon certain attributes of a context, and thus it obscures other important ones". In turn, the perception of the existence of some missing attributes becomes a source of uncertainty, which negatively affects the audience (Meyer 1981). This holds especially true if the missing information relates to an attribute that usually appears in the other available options (i.e., a common attribute), thus impeding comparisons (Kivetz et al. 2000).

Along this line of reasoning, one can conclude that an over-emphasized pro-social framing may have a negative effect as it hides other messages that the audience deems

\footnotetext{
$\overline{4}$ According to Hertog and McLeod (2001) p. 152: "When a particular set of concepts is clearly related to a frame, the number of times the concept is used reflects the emphasis of that concept or set of concepts in the text".
} 
important. This issue might be particularly relevant when the audience appreciation of a frame might be contingent on the joint display of other information that is typical in a particular context or in reference to a particular object. In further support of this view, evidence suggests that, in a market context, even the most socially conscious individuals (who value products' pro-social attributes) continue to be driven by their self-interest; they appreciate products' prosocial attributes, but only when they are provided in combination with - and not at the expense of - product functionality (Crane 2001). For instance, Auger et al. (2008) examine the purchasing behavior of individuals with varying degrees of social consciousness in relation to particular products. They find that the decisions of consumers who are highly conscious of the environmental impact of soap are substantially influenced by the effect of the soap on their skin, by its price, and by the appeal of its shape. Likewise, individuals in the animal-leather conscious segment for shoes give significant importance to shoes' fit, price, and shock absorption, in addition to social concerns. As to crowdfunding, Kim et al. (2016) show that on a reward-based crowdfunding platform, projects that over-emphasize accountability, by disclosing too much information on the project and its proponent, have a lower probability to succeed than other projects. The authors explain this result by arguing that a strong focus on accountability diverts backers' attention from other relevant attributes and thus hampers their ability to judge the project. The study of Moss et al. (2018) provides contrasting results. Here, projects displaying a balance between pro-social and economic aspects are funded more slowly than those that emphasize only a pro-social frame. However, it is important to note that, in the platform studied by these authors, displaying some balance of pro-social and economic values is a pre-condition for being accepted on the platform. More importantly, the funders have no direct self-interest in the project, besides that of being reimbursed, because the interest is earned by the platform, not the funders.

Overall, the arguments above suggest that the response of potential backers to pro-social framing might vary depending on the emphasis that proponents put on it, provided that the context enables self-interest. Specifically, we argue that in reward-based crowdfunding, where self-interest has a role, potential backers may appreciate a moderate emphasis on pro-social orientation, but too much emphasis on it may leave them with the uncomfortable perception that something important is missing in regard to other important dimensions, such as, for example, the individual benefits that projects may offer.

Thus, drawing from the discussion above, we formulate H1a and H1b as follows:

H1a A limited (but positive) emphasis on pro-social framing, as assessed by a low incidence of pro-social cues in the full project description, has a positive effect on crowdfunding projects' success.

H1b A strong emphasis on pro-social orientation, as assessed by a high incidence of pro-social cues in the full project description, has a negative effect on crowdfunding projects' success.

Hypothesis $1 \mathrm{~b}$ discusses strong emphasis on pro-social framing in terms of the incidence (frequency) of pro-social cues in a text. However, we noted before that strong emphasis may not just be a matter of how often cues appear in texts. The structure of the information has an important role in providing emphasis (Kulviwat et al. 2004; Zhang and Salvendy 2001). This is especially true in digital environments, where information has a hierarchical (hypertext) structure, which defines the access path of potential backers to projects (McKnight et al. 1991). Indeed, backers can access a crowdfunding project following two main paths. A first path is to land directly on the project's page through a web-link received, for instance, from a friend. A second path is to go on the platform home page. Here, each project appears as one piece of a mosaic displayed by its title, photo and blurb-a short promotional phrase-with a hyperlink that directs to the project's page. Figure 5 in the appendix shows an example of this mosaic display. A backer can then decide whether to click through the hyperlink and see the full project description or not. In sum, this second path channels information sequentially: backers view first the title and the blurb and access the rest of the information later, conditional on clicking. The hyperlink breaks the information structure of the textual project description and changes the opportunity to access it (McKnight et al. 1991). This mechanism resembles that of titles and headings in narrative texts. Especially when the text is long, complex or unfamiliar, titles and headings are crucial for capturing readers' attention. Moreover, they facilitate readers' comprehension by allowing them to form expectations and predict the content of the text (Zhang and Hoosain 2001).

We speculate that, because the title and blurb are made only of a few words (approximately ten words), placing prosocial cues in these may overshadow other project attributes, including functionalities that fulfill self-serving needs of potential backers. The illustration at Fig. 6 in the Appendix provides two screenshots from projects that present cues denoting various degrees of pro-social orientation in the title and blurb.

In conclusion, the full project description and its title and blurb are separate elements that stand in a hierarchical position. Placing pro-social cues in the title and blurb is equivalent to communicating a strong emphasis on prosocial stances, producing an effect similar to that stated in $\mathrm{H} 1 \mathrm{~b}$. We, therefore, formulate hypothesis $\mathrm{H} 2$ as follows. 
H2 A strong emphasis on pro-social framing, as assessed by the presence of pro-social cues in the title and blurb, has a negative effect on crowdfunding projects' success.

\section{Platform Crowdedness and Effectiveness of Pro-Social Framing on Crowdfunding Success}

Another distinctive feature of digital markets, besides the hyper-textual information structure, is crowdedness (Hansen and Haas 2001), i.e., the large number of alternatives that cram on digital markets and cause intense competition for attention (Hansen and Haas 2001; Simon 1986). More specifically, on crowdfunding platforms, projects struggle to capture the attention of potential backers because of the large number of alternative projects that compete for funding during the same time window. Because individuals have limited information processing abilities, ${ }^{5}$ a large set of projects imposes a heavy cognitive burden for searching, screening and choosing among alternatives (see, e.g., Broniarczyk and Griffin 2014). According to the literature on information processing, as the amount of information increases, individuals cope with this burden by resorting to cognitive strategies that make choices less accurate, but more doable (Bettman et al. 1998; Payne et al. 1993). One common strategy to economize on cognitive effort is restricting attention to a few selected attributes of an alternative (Bettman et al. 1998; Kivetz et al. 2000; Ocasio 2011; Shepherd et al. 2017). In other words, individuals focus on a few attributes to minimize costs and maximize the benefits of information processing. For instance, experiments show that increased amounts of information lead consumers to dedicate more time to evaluate the most important attributes of products, thereby being more selective in their information processing (Lurie 2004). In addition, linguistic cues guide individuals in this selection process by attracting their attention to recognizable and desirable attributes and thereby restricting the set of considered alternatives.

In line with these considerations, we posit that prosocial cues in crowdfunding projects can be used as selection attributes to lower the cognitive burden caused by the crowdedness of crowdfunding platforms. Indeed, pro-social cues-inserted either in the full project description or in the title and the blurb-demarcate a project from the others, thereby channeling backers' attention. This role of pro-social cues becomes more important as the crowdedness of platforms increases, i.e., as the number of projects competing

\footnotetext{
5 The concept of bounded rationality (March and Simon 1958) is well established in the economic and managerial literature. It points to the fact that individuals have limited ability to process information. This results from their limited computational capabilities and working memory.
}

for funding in the same time window grows. Accordingly, we argue that when crowdedness increases, pro-social framing, by demarcating a project over others, helps backers in the selection process and thereby increases the chance of a project's success. Hypothesis $\mathrm{H} 3$ follows.

H3 The relationship between pro-social framing and success is positively moderated by the crowdedness of the crowdfunding platform (i.e., the average number of active projects competing for attention in the reference period). Specifically, when the number of projects displayed on the platform increases, projects displaying a pro-social orientation have a higher probability of being funded compared to the situation in which only a few projects are competing on the platform.

In sum, by reflecting on framing theory and the contextual factors that shape the effectiveness of framing, we predict that the influence of pro-social framing on the success of crowdfunding campaigns is contingent on the level emphasis given to such framing and the crowdedness of information on the digital platform. We now turn to the empirical testing of the hypotheses.

\section{Methods and Results}

\section{Data Collection and Sample}

We started our data collection by downloading information on the population of over 75,000 campaigns launched on Kickstarter during seven consecutive quarters beginning from January 2016 till September 2017. Given our focus and research strategy, we wish to strike a suitable balance between the need for a large number of data for statistical power and the need for minimizing the measurement error in assessing pro-social orientation. To this end, we choose to restrict our sample in two ways. First, since our focus is on the pro-social framing in the presentation of tangible products and since Kickstarter has a high incidence of artistic and cultural projects offering non-tangible products, we restricted the sample to projects in the two categories of technology (e.g., apps, techy gadgets, 3D-printers), and design (e.g., backpacks, sunglasses, kitchen tools, toys). These categories were investigated in prior studies (Calic and Mosakowski 2016; Cholakova and Clarysse 2015). They account approximately for one-fifth of the total projects in the period and typically involve the production of a tangible product. Second, since our research strategy to assess prosocial framing involves using semantic analysis, we are concerned that the meaning associated with the pro-social words is consistent across the sample and does not vary over time, potentially inducing transient errors (McKenny et al. 2016). Therefore, we restricted the sample observation period to 
projects launched within the span of 12 months, i.e., from July 1, 2016 to June 30, 2017. The two restrictions led to an initial sample of 9851 projects, representing the population of Kickstarter projects in technology and design that were launched during four consecutive quarters beginning from July 1, 2016. From these, we removed 176 projects that were suspended during the campaign and 833 small projects whose target capital was less than $\$ 1000$. We further removed 211 projects with almost no textual descriptions (less than ten analyzable words). The final database consisted of 8631 projects.

For each project, we retrieved three sets of information identified by prior studies as determining crowdfunding success (Butticé et al. 2018). The first set of information concerns project characteristics and includes the following: target capital (Target_capital), backers who provide support (Backers), total capital pledged (Funds_pledged), country ( $D \_U S, D \_U K, D \_C A, D \_A U \_N Z$ ), and number of words in the project description (Text_length). The second set of information concerns platform activity. Specifically, we retrieved data on whether a project was shortlisted by the platform managers under the section "Project we love" (D_staffpick). This variable captures quality differentials across projects. We coded projects launched during weekends ( $D \_$weekend), as opposed to weekdays, with the aim of capturing potential changes in platform activity on weekends. We further computed the average daily number of projects that were active during the same time window of the focal project in the same category (Crowdedness), according to standard measures of the crowdedness in information processing studies (Lurie 2004). The third set of information comprises the textual description of the project. Specifically, for each project, we downloaded in separate.txt files the title, the blurb and the full description. We analyzed this corpus of texts to compute the metrics of pro-social framing, which were the main explanatory variables of the paper.

\section{Metrics of Pro-Social Framing}

We employ Computer-Aided Text Analysis (CATA) to assess the pro-social framing of crowdfunding projects. The application of CATA to the context of crowdfunding has some interesting methodological appeals. First, the project description posted on the platform represents, if not the entirety, at least the vast majority of information that potential backers can access on a project. Prior applications of CATA in management studies relied on the analysis of a small fraction of documents (e.g., the shareholders' letters) to infer general characteristics of a firm (e.g., its entrepreneurial orientation (Short et al. 2010); consequently, they were exposed to potentially large measurement errors. Second and partially related to the previous point, near-complete coverage of information reduces the potential measurement errors caused by impression-aimed information, which is a common problem in the adoption of CATA. Indeed, many CATA measures are based on not only incomplete but also biased information sets. Instead, in our case, the information set is rather complete and entirely covered in the analysis. Therefore, potential biases affect real-world decision-makers and CATA equally. Third, the short time span of crowdfunding campaigns (on average 30 days) limits the incidence of transient errors (McKenny et al. 2016), such as those occurring when a single measure accounts for a construct that can change over time.

The CATA methodology that we chose relies on an algorithm that assesses the pro-social framing of a project, based on the use of semantics expressing pro-social orientation, identified by the researchers in word lists built ad hoc. To build the word lists, we started by defining the construct of pro-social orientation, in accordance with prior literature. Specifically, we identify as pro-social orientation the awareness and care for others, the society and the environment and environmental issues; and the championing of the values of fairness and inclusiveness (see: Brickson 2007, Nilsson 2008; Secchi 2009). This definition elicits two related, but distinct dimensions nested in the construct: consciousness about the wellbeing of humans and of the society as a whole and consciousness about and the care for the environment. We chose to develop distinct word lists for each dimension.

To compile the word lists, we followed the methodology suggested by Short et al. (2010). First, we generated two large lists of words inductively. We included in the first list (hereafter, word list 1) words denoting 'ethics' in the Harvard-IV dictionary (i.e., pro-social orientation concerning humanity) and in the second list (hereafter, word list 2) the dictionary 'environment protection' (i.e., pro-social orientation concerning the environment) of the Laver-Garry Coding Scheme (Laver and Garry 2000). We further augmented each of the two lists searching for synonyms in the Rodale's Classic Synonym Finder (Rodale 1978). Second, we enriched word lists 1 and 2 deductively. We browsed a large pool of Kickstarter projects in search of words denoting pro-social orientation that were not yet in the aforementioned inductive word lists and continued the search iteratively until further browsing revealed no new words.

We tested the word lists' validity with the help of two experts, one of which was an author of the study, who had not been involved in the word list creation until that point, and the other was a person who had completed a $\mathrm{PhD}$ in the area of corporate social responsibility. The experts were instructed on the definitions of pro-social orientation adopted and asked to assess the meaning of the words in the specific context of crowdfunding (see Cornelissen and Werner 2014 for a similar approach). The two experts worked separately to provide initial independent assessment which resulted in an interrater agreement, corrected for the 
Table 1 Pro-social orientation in description and title/blurb

\begin{tabular}{lllllr}
\hline & Obs. & Mean & Std. Dev. & Min & Max \\
\hline Pro-social orientation in description of which & 8631 & 1.60 & 2.77 & 0.00 & 85.33 \\
No pro-social orientation & 3309 & 0.00 & 0.00 & 0.00 & 0.00 \\
Small pro-social orientation & 1348 & 0.69 & 0.21 & 0.16 & 1.04 \\
Medium pro-social orientation & 1322 & 1.45 & 0.25 & 1.05 & 1.92 \\
Large pro-social orientation & 1327 & 2.69 & 0.50 & 1.93 & 3.69 \\
Extra-large pro-social orientation & 1325 & 7.09 & 3.81 & 3.70 & 36.63 \\
Pro-social orientation in title and blurb & 8631 & 3.07 & 9.79 & 0.00 & 108.70 \\
\hline
\end{tabular}

random chance of agreement (Krippendorff 2004), equal to $\alpha=0.959$ for word list 1 and $\alpha=0.964$ for word list 2 , well above the conventionally accepted threshold of agreement of 0.8 (Krippendorff 2004; McKenny et al. 2016).

We computed the metric assessing pro-social framing with Diction 7, a commonly used software in scholarly studies employing CATA. In accordance to the hypotheses that we wished to test, we computed separate metrics for the title and blurb (average: 25 words) and for the full description (average: 689 words) of each project. The software enables handing documents of different length, by providing suitable ways to account for document length. Specifically, according to the users' guide suggestions, we used normalized scores for short documents (title and blurb), and unsegmented averages for long documents (full textual descriptions). ${ }^{6}$ The scores were computed separately for pro-social orientation concerning humanity (word list 1) and pro-social orientation concerning the environment (word list 2). The two scores were then summed to obtain the final single metric of pro-social orientation. The metric is capable to discern prosocial in both absolute (general understanding) and relative (within projects) terms.

We refined and tested the CATA in several ways. First, we tested a sample of software-generated metrics against human assessment. This screening suggested clearing off the word lists words with ambivalent meaning that caused biases in the software measures. In the end, word list 1 comprised 532 terms denoting pro-social orientation concerning humanity, whereas word list 2 included 180 terms denoting pro-social orientation concerning the environment. The

\footnotetext{
6 The unsegmented average score is computed as the normalized average of row scores obtained by an iterative procedure in which at the first round the score is computed on the first 500 words appearing in the document, and, at every subsequent round, the score is computed on the words at the prior round, plus a passage of the 500 subsequent words. As a result, words appearing at the beginning of the text are weighted more than those appearing at the end. This procedure is credited as a very precise handling of long documents. Full reference on the method is available in Diction 7 User Manual: https ://www.dictionsoftware.com/download.php?file=wp-content/uploa ds/2014/02/DICTION-7-Manual-2-26-14.pdf (Accessed March 6, 2019).
}

full lists are available from the authors upon request. For instance, terms in word list 1 include (in alphabetical order): abused, activist, adulterate, activism, advocacy, altruism, almsgiving, and anti-discrimination. ${ }^{7}$ Examples of terms in word list 2 (in alphabetical order) are: acid-rain, animalism, aridity, bio-fuel, bio-organic, biodegradable, and biodiversity. ${ }^{8}$ Second, we tested the consistency of the score across different time periods, finding no apparent variation of the average score from the first to the last quarter of the observation window. Third, we tested the concurrent validity of our metric by computing the correlation against other related constructs. We did so for measures obtained using the dictionary of Moss et al. (2018) and for separate dictionaries of potentially correlated meanings that are available in Diction 7. Specifically, we expected pro-social orientation to be strongly and positively correlated with "commonality" (defined as "language highlighting the agreed-upon values of a group and rejecting idiosyncratic modes of engagement") and "cooperation" (defined as "terms designating behavioral interactions among people that often result in a group product"). The results indicate a correlation and corroborate the expected concurrent validity. ${ }^{9}$

Table 1 reports the descriptive statistics of the final scores of pro-social framing computed using CATA for project complete descriptions and titles and blurbs. Looking at the variable of pro-social orientation in the project description

\footnotetext{
7 The following text, extracted from the project "Positive Beauty," provides an example of how terms in word list 1 (underlined) are used in context: "If girls are going to spend money on beauty, which inevitably they do as part of growing up and building their own selfesteem, we should use the opportunity to also teach them about being part of a global community, the responsibility that we all have to use our buying power wisely".

8 The following text, extracted from the project "CO2AltDelete," provides an example of how terms in word list 2 (underlined) are used in context: "We believe that greenhouse gas emission-especially of $\mathrm{CO} 2$ - is one of the biggest problems the world currently faces: manmade global warming is already causing serious problems across the world, and we believe that $\underline{\mathrm{CO} 2}$ emissions are not being reduced quickly enough to avoid much more serious problems in the near future."

9 Moss 0.233 ( $p$-value 0.000); Commonality 0.095 ( $p$-value 0.000 ); cooperation 0.223 ( $p$-value 0.000 ).
} 
Table 2 Variables used in models: construction and descriptive statistics

\begin{tabular}{|c|c|c|c|c|c|c|}
\hline Variable & Description & Obs. & Mean & Std. Dev. & Min & Max \\
\hline D_SUCCESS & Dummy $=1$ if successful at closure & 8631 & 0.30 & 0.46 & 0.00 & 1.00 \\
\hline Funds_pledged & Logarithm of the total funding in USD that were pledged at closure +1 & 8631 & 6.73 & 3.61 & 0.00 & 17.01 \\
\hline Backers & Logarithm of the number of backers that pledged money at closure +1 & 8631 & 3.14 & 2.18 & 0.00 & 11.95 \\
\hline Pro-social_description & Logarithm of pro-social orientation in project description +1 & 8631 & 0.73 & 0.74 & 0.00 & 3.63 \\
\hline S_pro-social & $\begin{array}{l}\text { Pro-social orientation in project description if pro-social orientation is in the } 1 \text { st } \\
\text { quartile; } 0 \text { otherwise }\end{array}$ & 8631 & 0.11 & 0.26 & 0.00 & 1.04 \\
\hline M_pro-social & $\begin{array}{l}\text { Pro-social orientation in project description if pro-social orientation is in the } \\
\text { 2nd quartile; } 0 \text { otherwise }\end{array}$ & 8631 & 0.22 & 0.53 & 0.00 & 1.92 \\
\hline L_pro-social & $\begin{array}{l}\text { Pro-social orientation in project description if pro-social orientation is in the } 3 \text { rd } \\
\text { quartile; } 0 \text { otherwise }\end{array}$ & 8631 & 0.41 & 0.99 & 0.00 & 3.69 \\
\hline XL_pro-social & $\begin{array}{l}\text { Pro-social orientation in project description if pro-social orientation is in the } 4 \text { th } \\
\text { quartile; } 0 \text { otherwise }\end{array}$ & 8631 & 1.09 & 2.96 & 0.00 & 36.63 \\
\hline D_pro-social_descr & Dummy $=1$ if pro-social orientation is displayed in project description & 8631 & 0.62 & 0.49 & 0.00 & 1.00 \\
\hline D_pro-social_tblurb & Dummy $=1$ if pro-social orientation is displayed in title or blurb & 8631 & 0.11 & 0.32 & 0.00 & 1.00 \\
\hline Target_capital & Logarithm of project target capital in thousand USD & 8631 & 2.84 & 1.32 & 0.00 & 9.90 \\
\hline D_staffpick & Dummy $=1$ if project was tagged as a "project we love" by platform & 8631 & 0.09 & 0.29 & 0.00 & 1.00 \\
\hline Text_length & Logarithm of the length of project description (in number of words) & 8631 & 6.17 & 0.93 & 2.40 & 8.52 \\
\hline D_weekend & Dummy $=1$ if campaign was launched in weekend & 8631 & 0.08 & 0.27 & 0.00 & 1.00 \\
\hline Crowdedness & $\begin{array}{l}\text { Logarithm of the average number of projects in the same category during } \\
\text { campaign }\end{array}$ & 8631 & 2.75 & 0.13 & 2.08 & 4.68 \\
\hline D_design & Category dummy $=1$ if category is design & 8631 & 0.62 & 0.49 & 0.00 & 1.00 \\
\hline D_technology & Category dummy $=1$ if category is technology & 8631 & 0.38 & 0.49 & 0.00 & 1.00 \\
\hline D_US & Country area dummy $=1$ if project location is USA & 8631 & 0.82 & 0.39 & 0.00 & 1.00 \\
\hline D_UK & Country area dummy $=1$ if project location is UK & 8631 & 0.07 & 0.25 & 0.00 & 1.00 \\
\hline D_CA & Country area dummy $=1$ if project location is Canada & 8631 & 0.04 & 0.18 & 0.00 & 1.00 \\
\hline D_AU_NZ & Country area dummy $=1$ if project location is Australia or New Zealand & 8631 & 0.02 & 0.14 & 0.00 & 1.00 \\
\hline
\end{tabular}

(Pro-social_description), we notice that, out of 8631 projects, $5322(61.7 \%)$ display some level of pro-social orientation in the project description, as opposed to 3309 projects (approximately $38.3 \%$ ) that do not. Slightly more than one in ten projects $(11.2 \%)$ displays pro-social cues in the title or blurb, a low proportion related to the small number of words in title and blurb. Consequently, we synthesize the pro-social orientation in the title and blurb using a dummy variable taking a value of 1 if pro-social orientation is greater than zero (D_Prosocial_tblurb).

Table 2 reports information on variable construction and descriptive statistics (mean, standard deviation, minimum and maximum) for all the variables used in the analyses and in the robustness checks. Continuous and count variables were logarithm-transformed in the case of exceedingly high kurtosis.

A preliminary analysis of the correlation shows that prosocial orientation is not correlated to staff_pick (corr $=0.020$; $p$-value $>0.05$ ), a variable that could capture in part project quality. The variance inflation factor (VIF) reveals no major problems of multicollinearity within the set of variables used. The VIF of the variables ranges from a minimum of 1.05 and a maximum of 1.31 . The mean VIF is 2.04.

\section{Results}

We seek to study the effects of pro-social framing on the likelihood that a crowdfunding project succeeds in raising funds. Consequently, our main dependent variable is a dummy that takes a value of 1 if the amount pledged at the closure date of the campaign is equal to or greater than the target capital and 0 otherwise. We discuss models with alternative dependent variables (total backers and total amount pledged) in the robustness checks. Given the binary nature of the dependent variable, we use a Logit specification with robust standard errors. Table 3 reports the results of the estimates. To improve the readability of the model estimates, we standardized the coefficients of the continuous variables (mean $=0$; standard deviation =1). Model 1 of Table 3 shows the baseline estimate, which includes the control variables related to project characteristics and platform activity, as mentioned above. Dummy variables for product category and country area were included in all models, although their coefficients 
Table 3 Results of the estimates

\begin{tabular}{|c|c|c|c|c|c|c|}
\hline & (1) & (2) & (3) & (4) & (5) & (6) \\
\hline Pro-social_description & & $\begin{array}{l}-0.15 \\
(0.03)^{* * *}\end{array}$ & $\begin{array}{l}-0.17 \\
(0.04)^{* * *}\end{array}$ & & & $\begin{array}{l}-0.18 \\
(0.04)^{* * *}\end{array}$ \\
\hline Sq_pro_social_descr & & & $\begin{array}{l}0.00 \\
(0.00)\end{array}$ & & & \\
\hline S_pro-social & & & & $\begin{array}{c}0.27 \\
(0.11)^{*}\end{array}$ & & \\
\hline M_pro-social & & & & $\begin{array}{r}-0.06 \\
(0.06)\end{array}$ & & \\
\hline L_pro-social & & & & $\begin{array}{c}-0.06 \\
(0.03)^{*}\end{array}$ & & \\
\hline XL_pro-social & & & & $\begin{array}{l}-0.04 \\
\quad(0.01)^{* * *}\end{array}$ & & \\
\hline D_pro-social_tblurb & & & & & $\begin{array}{l}-0.30 \\
(0.09)^{* * *}\end{array}$ & $\begin{array}{l}-0.16 \\
(0.10)^{+}\end{array}$ \\
\hline Target_capital & $\begin{array}{l}-0.77 \\
(0.03)^{* * *}\end{array}$ & $\begin{array}{l}-0.77 \\
(0.03) * * *\end{array}$ & $\begin{array}{l}-0.77 \\
(0.03)^{* * *}\end{array}$ & $\begin{array}{l}-0.77 \\
(0.03)^{* * *}\end{array}$ & $\begin{array}{l}-0.77 \\
(0.03)^{* * *}\end{array}$ & $\begin{array}{l}-0.77 \\
(0.03)^{* * *}\end{array}$ \\
\hline D_staffpick & $\begin{array}{l}2.53 \\
(0.11)^{* * *}\end{array}$ & $\begin{array}{l}2.53 \\
(0.11) * * *\end{array}$ & $\begin{array}{l}2.53 \\
(0.11)^{* * *}\end{array}$ & $\begin{array}{l}2.54 \\
(0.11)^{* * *}\end{array}$ & $\begin{array}{l}2.53 \\
(0.11)^{* * *}\end{array}$ & $\begin{array}{l}2.53 \\
(0.11)^{* * *}\end{array}$ \\
\hline Text_length & $\begin{array}{l}0.81 \\
(0.04)^{* * *}\end{array}$ & $\begin{array}{l}0.83 \\
(0.04) * * *\end{array}$ & $\begin{array}{l}0.84 \\
(0.04) * * *\end{array}$ & $\begin{array}{l}0.79 \\
(0.04) * * *\end{array}$ & $\begin{array}{l}0.78 \\
(0.04) * * *\end{array}$ & $\begin{array}{l}0.83 \\
(0.04)^{* * *}\end{array}$ \\
\hline D_weekend & $\begin{array}{l}-0.40 \\
(0.11)^{* * *}\end{array}$ & $\begin{array}{l}-0.40 \\
(0.11)^{* * *}\end{array}$ & $\begin{array}{l}-0.40 \\
(0.11)^{* * *}\end{array}$ & $\begin{array}{l}-0.40 \\
(0.11)^{* * *}\end{array}$ & $\begin{array}{l}-0.40 \\
(0.11)^{* * *}\end{array}$ & $\begin{array}{l}-0.40 \\
(0.11)^{* * *}\end{array}$ \\
\hline Constant & $\begin{array}{l}-1.72 \\
(0.14) * * *\end{array}$ & $\begin{array}{l}-1.76 \\
(0.14)^{* * *}\end{array}$ & $\begin{array}{l}-1.77 \\
(0.14)^{* * *}\end{array}$ & $\begin{array}{r}-1.69 \\
(0.14)^{* * *}\end{array}$ & $\begin{array}{l}-1.70 \\
(0.14)^{* * *}\end{array}$ & $\begin{array}{l}-1.62 \\
(0.14) * * *\end{array}$ \\
\hline No & 8631.0 & 8631.0 & 8631.0 & 8631.0 & 8631.0 & 8631.0 \\
\hline Pseudo $R^{2}$ & 0.2322 & 0.2347 & 0.2348 & 0.2354 & 0.2333 & 0.2350 \\
\hline
\end{tabular}

Logit models. Dependent variable: D_SUCCESS. Country area dummies included. Category dummies included. Robust standard error in parentheses

${ }^{+} p<0.1 ; * p<0.05 ; * * p<0.01 ; * * * p<0.001$

were not reported in tables for the sake of brevity. ${ }^{10}$ The baseline estimate shows a satisfying overall fit (McFadden-Pseudo $R^{2}=0.232$ ). The variables of target amount (Target_capital), project inclusion among the 'Project we love' (D_staffpick) and text length (Text_length) take signs in line with those of prior studies (Butticè et al. 2018; Colombo et al. 2015; Kuppuswamy and Bayus 2017; Mollick 2014). Interestingly, projects launched during the weekends ( $D \_$weekend) exhibit lower success rates compared to those launched during weekdays.

Before testing our hypotheses on the effect of different levels of pro-social framing in the project description, we report in Model 2 of Table 3 the estimates of the model in which a single continuous variable of pro-social orientation in the project descriptions (Pro-social_description) is included. The coefficient of Pro-social_description is

\footnotetext{
$\overline{10}$ Project duration was not found to be statistically significant and was omitted from models.
}

statistically significant at conventional confidence levels and indicates that the average effect of pro-social orientation in the project description is negative. The fitness improves (McFadden-Pseudo $R^{2}=0.234$ ) compared to the baseline, and the tests on model fit suggest a strong preference for the inclusion of the variable (diff $\mathrm{BIC}=17.199$ ).

To have a more fine-grained view on the effect of prosocial framing, we test our hypotheses H1a and H1b. To this end, we begin by including in the model the simple and quadratic form of the variable capturing pro-social orientation in the project description, expecting a positive and negative sign, respectively. However, the simple variable of pro-social orientation takes a negative and significant value, while the quadratic form is not statistically different from zero at conventional significance values (Model 3 , Table 3). To investigate further the potential existence of non-linear effects of degree greater than two, we attempted different estimates with sets of split variables that capture different levels of pro-social orientation. Model 4 of Table 3 reports the estimate of a model that fits well the data 
(alternative models are discussed in the robustness checks). This includes the four quartiles of pro-social orientation estimated against the omitted baseline of zero pro-social orientation. The coefficient estimates show that for low, but nonzero, levels of pro-social orientation displayed in the project description (S_pro-social), pro-social framing is positively correlated to project success $(p<0.050)$. For medium levels of pro-social orientation in the project description (M_prosocial), the effect is neutral; for large ( $L \_$pro-social) and very large (XL_pro-social) levels of pro-social orientation the effects are negatively correlated to project success $(p<0.050 ; p<0.001$, respectively). Note that the coefficients are expressed against the baseline of no social orientation and their comparison in sign and magnitude shows a gradient that takes the whole spectrum from positive, to neutral, to negative, as the emphasis on pro-social orientation grows. This is corroborated by the fact that the difference between the coefficients of small and medium levels of pro-social orientation is statistically significant $\left(\chi^{2}=10.41 ; p<0.01\right)$, as is the difference between small and large levels of pro-social orientation $\left(\chi^{2}=10.30 ; p<0.01\right)$, and between the small and very large levels of pro-social orientation $\left(\chi^{2}=8.43 ; p\right.$ $<0.01)$. Overall, the results provide moderate support that small levels of pro-social orientation in the project description can be associated with a greater probability of success (H1a), compared to no social orientation. Moreover, they provide strong support that a high emphasis on pro-social orientation, i.e., when very high levels of pro-social orientation are displayed in the project description, is associated with a lower probability of success (H1b).

Regarding the magnitude, a shift from zero to small levels of social orientation (S_pro-social) is associated with an increase of $2.3 \%$ in the probability of success. A shift from zero to large levels of pro-social orientation ( $L_{-}$pro-social $)$is associated with a decrease of $3.4 \%$ in the probability of success and a shift from zero to very large levels of pro-social orientation (XL_pro-social) is associated with a decrease of $5.9 \%$ in the probability of success.

In Model 5 of Table 3, we report the results of the estimate through which we test $\mathrm{H} 2$. In this case, we focus on linguistic cues pointing to pro-social orientation displayed in the title and blurb of projects, consistent with the idea that, in online markets, information is processed hierarchically. We run a regression that includes the baseline and a dummy variable that equals 1 for projects with a pro-social framing visible from title and blurb (D_pro-social_tblurb). As predicted, the coefficient of the dummy variable of pro-social orientation in the title and blurb (D_pro-social_tblurb) is negative and significant at conventional levels. The magnitude is quite sizable: projects that display linguistic cues pointing to pro-social orientation in the title and blurb have on average a $-4.7 \%$ lower probability of success compared to those that do not display pro-social orientation in the title and blurb. Interestingly, the magnitude of the coefficient is similar to the one found for large/very large levels of prosocial orientation in the description. Model 6 of Table 3 shows that the negative sign of the pro-social variable in title and blurb holds even when including a variable of prosocial orientation in the project description, although the coefficient is only weakly statistically significant $(p<0.05)$, in part because the two variables are correlated (pairwise correlation $=0.38, p<0.001$ ).

Overall, the results support $\mathrm{H} 2$ that the display of prosocial cues in the title or the blurb confers a strong emphasis to the pro-social framing of the project and is associated with a lower probability of success, thereby mirroring the negative effect of high levels of pro-social orientation in the full project description (H1b).

The results of the econometric estimates were then corroborated by interviews that we conducted in the summer of 2019 with four managers of crowdfunding platforms based in the US and Europe. In particular, two separate interviewees reported that, in their guidelines to project proponents, they suggest to avoid excess emphasis on pro-social features, and even went as far as banning the use of pro-social advocacy in titles, because they believe it would obscure other features that define the quality of the project.

To test hypothesis H3, we investigate the effect of pro-social framing under different amounts of crowdedness of the platform by means of models with interaction terms. Recall that we measure crowdedness by means of a variable (Crowdedness) that counts the number of project campaigns open for funding in the day of the launch of the focal project and in the same project category. Model 1 of Table 4 shows the baseline model, in which we include two dummy variables indicating prosocial framing in the description (D_pro-social_description) and in title/blurb (D_pro-social_tblurb) and the crowdedness variable (Crowdedness) separately. We choose to include a single dummy for pro-social framing in the project description to improve the readability of the interaction model (see related baseline model in Table 5, Model 1). The coefficients of both dummy variables are negative and significant at conventional levels ( $p<0.05 ; p<0.01$, respectively), whereas the coefficient of the crowdedness variable is nearly zero and not statistically significant $(p=0.354)$. In Model 2 of Table 4 , we include the dummy variable indicating pro-social framing in the project description (D_pro-social_description), the crowdedness variable (Crowdedness) and their interaction term (D_pro-social_descr X Crowdedness). The coefficient of pro-social framing remains negative and significant $(p<0.05)$; the coefficient of crowdedness remains nearly zero and not statistically significant $(p=0.312)$. In contrast, the interaction term is positive and statistically significant $(p<0.05)$. Because of the 
Table 4 Interaction effects

\begin{tabular}{|c|c|c|c|}
\hline & (1) & (2) & (3) \\
\hline D_pro-social_description & $\begin{array}{l}-0.13 \\
(0.06)^{*}\end{array}$ & $\begin{array}{l}-0.16 \\
(0.06)^{*}\end{array}$ & \\
\hline D_pro-social_tblurb & $\begin{array}{l}-0.27 \\
(0.09) * *\end{array}$ & & $\begin{array}{l}-0.31 \\
(0.09)^{* * *}\end{array}$ \\
\hline Crowdedness & $\begin{array}{l}0.03 \\
(0.03)\end{array}$ & $\begin{array}{l}-0.04 \\
(0.04)\end{array}$ & $\begin{array}{l}-0.01 \\
(0.03)\end{array}$ \\
\hline $\begin{array}{l}\text { D_pro-social_descr } X \text { crowded- } \\
\text { ness }\end{array}$ & & $\begin{array}{l}0.11 \\
(0.05)^{*}\end{array}$ & \\
\hline $\begin{array}{l}\text { D_pro-social_blurb } X \text { crowded- } \\
\text { ness }\end{array}$ & & & $\begin{array}{l}0.17 \\
(0.08)^{*}\end{array}$ \\
\hline Target_capital & $\begin{array}{l}-0.77 \\
(0.03) * * *\end{array}$ & $\begin{array}{l}-0.77 \\
(0.03) * * *\end{array}$ & $\begin{array}{l}-0.77 \\
(0.03)^{* * *}\end{array}$ \\
\hline D_staffpick & $\begin{array}{l}2.53 \\
(0.11) * * *\end{array}$ & $\begin{array}{l}2.53 \\
(0.11)^{* * *}\end{array}$ & $\begin{array}{l}2.53 \\
(0.11)^{* * *}\end{array}$ \\
\hline Text_length & $\begin{array}{l}0.84 \\
(0.04) * * *\end{array}$ & $\begin{array}{l}0.85 \\
(0.04) * * *\end{array}$ & $\begin{array}{l}0.81 \\
(0.04)^{* * *}\end{array}$ \\
\hline D_weekend & $\begin{array}{l}-0.40 \\
(0.11)^{* * *}\end{array}$ & $\begin{array}{l}-0.39 \\
(0.11)^{* * *}\end{array}$ & $\begin{array}{l}-0.40 \\
(0.11)^{* * *}\end{array}$ \\
\hline Constant & $\begin{array}{l}-1.64 \\
(0.14)^{* * *}\end{array}$ & $\begin{array}{l}-1.64 \\
(0.14)^{* * *}\end{array}$ & $\begin{array}{l}-1.70 \\
(0.14)^{* * *}\end{array}$ \\
\hline No & 8631.0 & 8631.0 & 8631.0 \\
\hline Pseudo $R^{2}$ & 0.2338 & 0.2333 & 0.2337 \\
\hline
\end{tabular}

Logit models. Dependent variable: D_SUCCESS. Country area dummies included. Category dummies included. Robust standard error in parentheses

${ }^{*} p<0.05 ; * * p<0.01 ; * * * p<0.001$

non-linear nature of the Logit model, we investigate further the effect of the interaction term at different levels of crowdedness, by means of a graphical inspection based on the estimate shown in Model 2 of Table 4. Figure 1 shows the average marginal effects of no prosocial orientation (dash-dot line) and pro-social orientation (solid line) on the chances of success ( $y$-axis), as the level of crowdedness ( $x$-axis) increases from the 5 th to the 95th percentile of its distribution. The bars represent $95 \%$ confidence intervals. The graph shows that displaying pro-social orientation in the project description is associated with lower chances of success of a campaign, compared to no pro-social orientation (consistent with Models 2 and 6 of Table 3). However, this is so only for small to median values of crowdedness. From median to high levels of crowdedness, the negative effect of prosocial orientation on the probability of success vanishes and is no longer different from zero at standard confidence levels.

Finally, we repeat the analysis by looking at the interaction between no pro-social orientation in the title/ blurb and the level of crowdedness (D_pro-social_tblurb
$X$ Crowdedness). The results are reported in Model 3 of Table 4 and they are further investigated graphically in Fig. 2. Again, the display of no pro-social orientation in the title and blurb is negatively associated with project success for low to medium-high levels of crowdedness (consistent with H2), but the effect vanishes for levels of crowdedness equal to or above the 80th percentile.

Overall, these results corroborate $\mathrm{H} 3$ in the sense that increasing crowdedness reduces the negative effect of prosocial orientation on the success of reward-based crowdfunding projects.

\section{Robustness Checks}

We performed a set of additional analyses to investigate our results further and test their robustness. First, the results are robust when choosing alternative thresholds to define the levels of the categorical variables of prosocial orientation used in Model 4 of Table 3. By way of example, Model 2 of Table 5 reports a breakdown of split variables of pro-social orientation for each decile of the distribution of pro-social orientation in the text description. Second, we tested that the results of curvilinear effects-positive for modest emphasis of pro-social orientation and negative for high emphasis of pro-social orientation (either in text or in title/blurb)_-hold unchanged when we use sheer frequency counts of pro-social cues, instead of Diction 7 scores.

Third, the results are robust to the choice of alternative dependent variables representing performance. Specifically, we run robust OLS estimates with models mirroring the main estimates of Table 3 in which the dependent variables are the log of the total number of backers (Backers) (Models 1, 2 of Table 6) and the log of the total pledges (Funds_pledged) (Models 3, 4 of Table 6), instead of the binary variable of success. The results are consistent with those of the Logit estimates and corroborate the hypotheses. Fourth, the results are unchanged if we limit the sample to either product category: technology only (Models 1, 2 Table 7) or design only (Models 3, 4, Table 7).

Fifth, our CATA measures of pro-social orientation are performed on the language of project description. They are not performed on the language used in the videos. The interviews that we conducted with platform managers suggested that crowdfunders use both (project description and video language) as sources of information. Therefore, by not looking at the language of videos, our measures of pro-social orientation are subjected to measurement errors. The large-sample used in the study would make the analyses robust to the presence of measurement errors for omitted variables, as long as these are 
Table 5 Robustness checks

\begin{tabular}{|c|c|c|c|c|}
\hline Dependent var & $\begin{array}{l}(1) \\
\text { Logit } \\
\text { D_SUCCESS }\end{array}$ & $\begin{array}{l}(2) \\
\text { Logit } \\
\text { D_SUCCESS }\end{array}$ & $\begin{array}{l}\text { (3) } \\
\text { OLS } \\
\text { Funds_pledged }\end{array}$ & $\begin{array}{l}\text { (4) } \\
\text { OLS } \\
\text { Funds_pledged }\end{array}$ \\
\hline D_pro-social_descr & $\begin{array}{l}-0.16 \\
(0.06)^{* *}\end{array}$ & & $\begin{array}{l}-0.24 \\
(0.04)^{* * *}\end{array}$ & \\
\hline D_pro-social_tblurb & & & & $\begin{array}{l}-0.35 \\
(0.10)^{* * *}\end{array}$ \\
\hline Pro-social_d_0_10 & & $\begin{array}{c}0.22 \\
(0.24)\end{array}$ & & \\
\hline Pro-social_d_10_20 & & $\begin{array}{l}0.29 \\
(0.14)^{* *}\end{array}$ & & \\
\hline Pro-social_d_20_30 & & $\begin{array}{c}0.04 \\
(0.11)\end{array}$ & & \\
\hline Pro-social_d_30_40 & & $\begin{array}{r}-0.04 \\
(0.09)\end{array}$ & & \\
\hline Pro-social_d_40_50 & & $\begin{array}{r}-0.10 \\
(0.07)\end{array}$ & & \\
\hline Pro-social_d_50_60 & & $\begin{array}{r}-0.09 \\
(0.05)\end{array}$ & & \\
\hline Pro-social_d_60_70 & & $\begin{array}{c}-0.08 \\
(0.04)^{+}\end{array}$ & & \\
\hline Pro-social_d_70_80 & & $\begin{array}{r}-0.05 \\
(0.03)\end{array}$ & & \\
\hline Pro-social_d_80_90 & & $\begin{array}{l}-0.06 \\
\quad(0.02)^{* * *}\end{array}$ & & \\
\hline Pro-social_d_90_100 & & $\begin{array}{l}-0.04 \\
(0.01)^{* * *}\end{array}$ & & \\
\hline Std_ln_goal & $\begin{array}{l}-0.77 \\
(0.03) * * *\end{array}$ & $\begin{array}{l}-0.77 \\
(0.03)^{* * *}\end{array}$ & $\begin{array}{l}0.01 \\
(0.03)\end{array}$ & $\begin{array}{l}0.00 \\
(0.03)\end{array}$ \\
\hline D_staffpick & $\begin{array}{l}2.53 \\
(0.11)^{* * *}\end{array}$ & $\begin{array}{l}2.53 \\
(0.11)^{* * *}\end{array}$ & $\begin{array}{l}3.19 \\
(0.08) * * *\end{array}$ & $\begin{array}{l}3.20 \\
(0.08) * * *\end{array}$ \\
\hline Std_ln_length & $\begin{array}{l}0.84 \\
(0.04)^{* * * *}\end{array}$ & $\begin{array}{l}0.79 \\
(0.04)^{* * *}\end{array}$ & $\begin{array}{l}1.41 \\
(0.04) * * *\end{array}$ & $\begin{array}{l}1.39 \\
(0.04) * * *\end{array}$ \\
\hline D_weekend & $\begin{array}{l}-0.40 \\
(0.11)^{* * *}\end{array}$ & $\begin{array}{l}-0.40 \\
(0.11)^{* * *}\end{array}$ & $\begin{array}{l}-0.45 \\
(0.12)^{* * *}\end{array}$ & $\begin{array}{l}-0.46 \\
(0.11)^{* * *}\end{array}$ \\
\hline Constant & $\begin{array}{l}-1.64 \\
(0.14)^{* * *}\end{array}$ & $\begin{array}{r}-1.67 \\
(0.14)^{* * *}\end{array}$ & $\begin{array}{l}5.61 \\
(0.17)^{* * *}\end{array}$ & $\begin{array}{l}5.52 \\
(0.17)^{* * *}\end{array}$ \\
\hline No & 8631.0 & 8631.0 & 8631.0 & 8631.0 \\
\hline Pseudo $R^{2}$ & 0.2329 & 0.2354 & & \\
\hline$R^{2}$ & & & 0.3317 & 0.3305 \\
\hline
\end{tabular}

Country area dummies included. Category dummies included. Robust standard error in parentheses ${ }^{+} p<0.1 ; * p<0.05 ; * * p<0.01 ; * * * p<0.001$

randomly distributed. It would conversely produce biased estimates if the language of videos differs systematically (non-randomly) from the language of the project's description. Although it is implausible that this is the case, we performed additional checks. We sampled 207 projects from the entire population, transcribed the videos, and computed our two CATA measures of pro-social orientation, first separately and then jointly, on the transcripts of videos. The measures are all highly correlated to those obtained from the CATA analysis of project descriptions, ${ }^{11}$ suggesting that the measurement error

11 Pro-social concerning humanity: $0.315 p$-value:0.000; Pro-social concerning environment: $0.717 p$-value 0.000 ; Pro-social (final measure): $0.378 p$-value: 0.000 . 


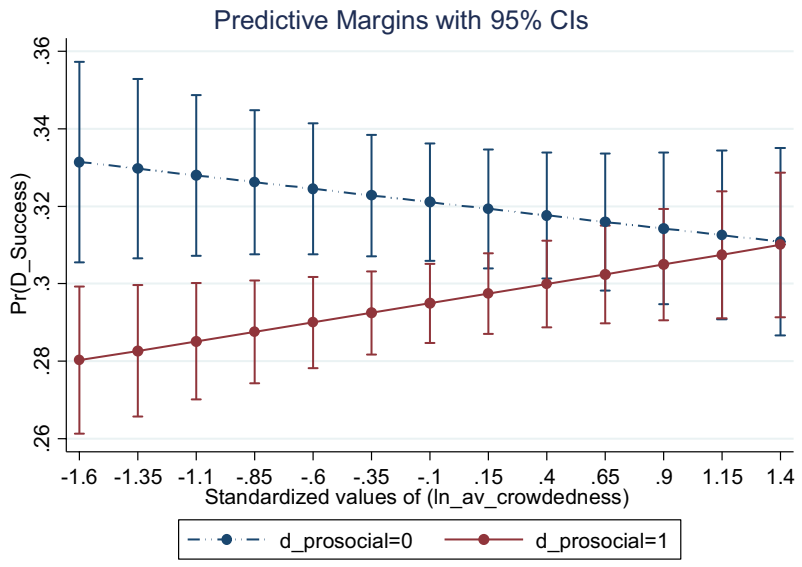

Logit model estimate (Table IV, model 2)

Fig. 1 Effect of probability of success (vertical axis) of pro-social orientation in project description (solid line) and zero pro-social orientation in project description (dash-dot line) on levels of crowdedness (horizontal axis). Logit model estimate (Table 4, Model 2)

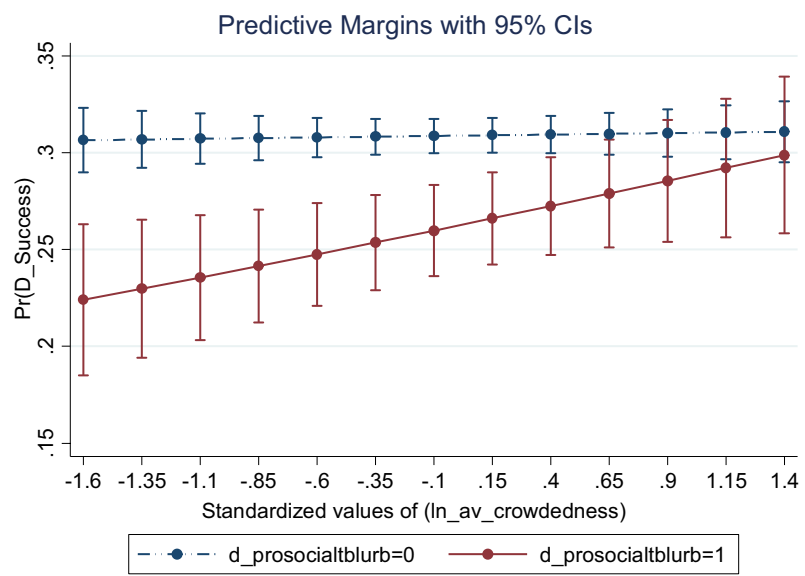

Logit model estimate (Table IV, model 3)

Fig. 2 Effect on probability of success (vertical axis) of pro-social orientation in project title (solid line) and zero pro-social orientation in project title (dash-dot line) for increasing levels of crowdedness (horizontal axis). Logit model estimate (Table 4, Model 3)

that we potentially include by not screening the video transcripts is likely random, and, thus, not a concern.

Sixth, we test for the presence of potentially confounding factors of no pro-social orientation, by controlling for potentially meaningful CATA-based language metrics that are available as 'master variables' in Diction 7. These are optimism, defined as "language endorsing some person, group, concept or event or highlighting their positive entailments"; and realism, defined as "language describing tangible, immediate, recognizable
Table 6 Robustness checks

\begin{tabular}{lll}
\hline Dependent variable & $\begin{array}{l}\text { (1) OLS } \\
\text { Backers }\end{array}$ & $\begin{array}{l}\text { (2) OLS } \\
\text { Backers }\end{array}$ \\
\hline Ln_pro-social_descr & -0.19 & \\
& $(0.03)^{* * *}$ & \\
D_pro-social_tblurb & & -0.28 \\
& & $(0.06)^{* * *}$ \\
Std_ln_goal & -0.10 & -0.10 \\
& $(0.02)^{* * *}$ & $(0.02)^{* * *}$ \\
D_staffpick & 2.23 & 2.24 \\
& $(0.06)^{* * *}$ & $(0.07)^{* * *}$ \\
Std_ln_length & 0.77 & 0.75 \\
& $(0.02)^{* * *}$ & $(0.02)^{* * *}$ \\
D_weekend & -0.37 & -0.38 \\
& $(0.06)^{* * *}$ & $(0.06)^{* * *}$ \\
Constant & 2.48 & 2.40 \\
& $(0.10)^{* * *}$ & $(0.10)^{* * *}$ \\
No observations & 8631.00 & 8631.00 \\
R^2 & 0.3231 & 0.3209 \\
\hline
\end{tabular}

OLS models. Country area dummies included. Category dummies included. Robust standard error in parentheses

$* * * p<0.001$

Table 7 Robustness checks

\begin{tabular}{lllll}
\hline & $(1)$ & $(2)$ & $(3)$ & $(4)$ \\
& Technology & Technology & Design & Design \\
\hline Ln_pro_social_ & -0.16 & & -0.24 & \\
descr & $(0.06)^{*}$ & & $(0.05)^{* * *}$ & \\
Std_ln_goal & -0.72 & -0.73 & -0.82 & -0.82 \\
& $(0.05)^{* * *}$ & $(0.05)^{* * *}$ & $(0.04)^{* * *}$ & $(0.04)^{* * *}$ \\
D_staffpick & 2.63 & 2.64 & 2.34 & 2.33 \\
& $(0.15)^{* * *}$ & $(0.15)^{* * *}$ & $(0.15)^{* * *}$ & $(0.15)^{* * *}$ \\
Std_lnlength & 0.95 & 0.94 & 0.74 & 0.71 \\
& $(0.06)^{* * *}$ & $(0.06)^{* * *}$ & $(0.05)^{* * *}$ & $(0.05)^{* * *}$ \\
D_weekend & -0.44 & -0.44 & -0.36 & -0.35 \\
& $(0.17)^{* *}$ & $(0.17)^{* *}$ & $(0.14)^{*}$ & $(0.14)^{*}$ \\
D_pro-social_ & & -0.37 & & -0.25 \\
tblurb & & $(0.13)^{* * *}$ & & $(0.12)^{*}$ \\
Constant & -1.70 & -1.74 & -0.68 & -0.80 \\
& $(0.19)^{* * *}$ & $(0.19)^{* * *}$ & $(0.19)^{* * *}$ & $(0.19)^{* * *}$ \\
No & 4691.0 & 4691.0 & 3940.0 & 3940.0 \\
Pseudo $R^{2}$ & 0.2380 & 0.2382 & 0.1775 & 0.1746 \\
\hline
\end{tabular}

Logit models. Dependent variable: D_SUCCESS. Country area dummies included. Robust standard error in parentheses

${ }^{*} p<0.05 ; * * p<0.01 ; * * * p<0.001$

matters that affect people's everyday lives." The inclusion of the two variables improves the fit marginally (with realism having a negative coefficient and optimism 


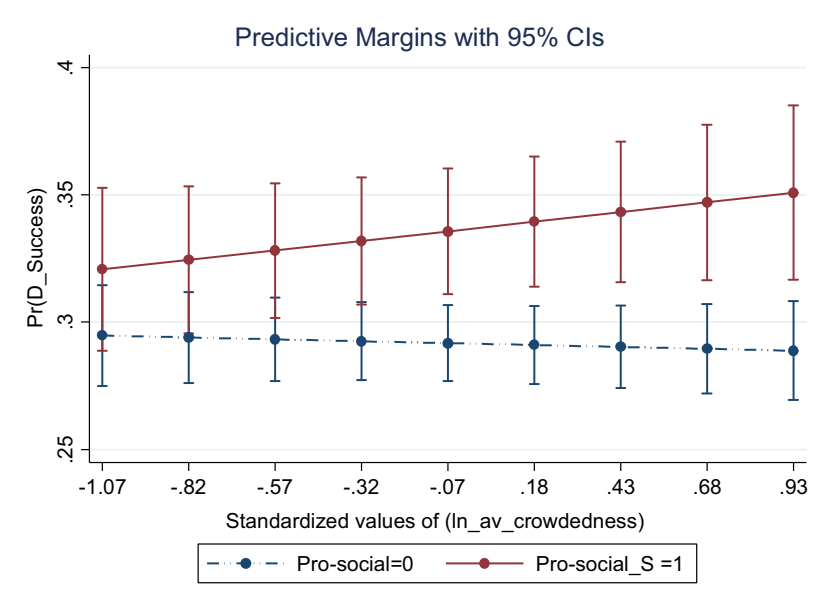

Logit estimates - Subsample (sample split in robustness checks section)

Fig. 3 Effect on the probability of success (vertical axis) of low prosocial orientation in textual description (solid line) and zero prosocial orientation in textual description (dash-dot line) for increasing levels of crowdedness (horizontal axis). Logit estimates-subsample (sample split in robustness checks section)

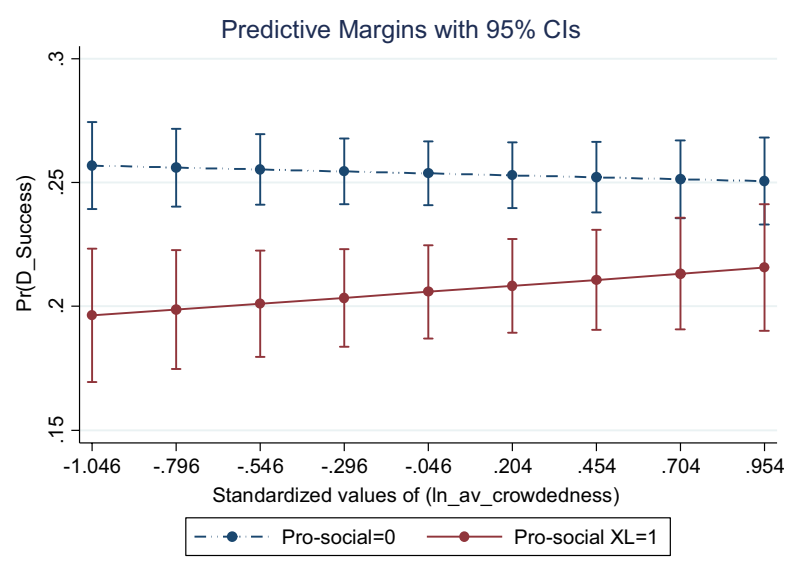

Logit estimates- Sub-sample (sample split in robustness checks section)

Fig. 4 Effect on probability of success (vertical axis) of high prosocial orientation in textual description (solid line) and no pro-social orientation in textual description (dash-dotted line) for increasing levels of crowdedness (horizontal axis). Logit estimates-subsample (sample split in robustness checks section)

having a positive coefficient). All results of the main models in Tables 3 and 4 hold and the magnitude of the marginal effects of the variable of interest remains almost unchanged.

Seventh, the results of Table 4 do not change if we include monthly dummy variables that account for variations of crowdedness caused by seasonality. The tables were omitted for brevity, but are available from the authors upon request. Finally, to get some insights into the moderating effect of crowdedness when we take into account the different level of emphasis on pro-social orientation we split the data into five subsamples, each related to a different level of pro-social orientation: zero (no-pro-social), low, medium, high and very high. We then run four Logit model estimates by iteratively including different subsamples. Specifically, in each estimate, we include always the zero (pro-social orientation) subsample plus either one of the other four subsamples. The results of these estimations are not provided here, but are available upon request and confirm all the results and further validate the positive effect of a low emphasis of pro-social orientation on crowdfunding success and the negative effect of a high emphasis of pro-social orientation on crowdfunding success. We then tested the interaction effect between crowdedness and pro-social orientation, for each level of pro-social orientation separately. Figures 3 and 4 show the effect of low pro-social orientation and of very high pro-social orientation at different levels of crowdedness. Figure 3 indicates that, for low levels of crowdedness, projects with a small emphasis on pro-social orientation have a higher-and statistically significant-likelihood of success than projects not displaying a pro-social orientation (zero pro-social). Conversely, for high levels of crowdedness, the negative effect of displaying very high levels of pro-social orientation (see H2) fades away until it becomes not statistically significant (Fig. 4). However, we do not find any statistically significant moderating effect of crowdedness on displaying medium or high levels of pro-social orientation (figures omitted for brevity but are available upon request).

\section{Discussion and Conclusion}

We study how pro-social framing affects funding success in the context of reward-based crowdfunding, where potential backers are motivated by both social concerns and self-interest. Our results show that, while a moderate emphasis on pro-social framing is beneficial, too much emphasis on pro-social framing backfires. The effect of pro-social emphasis varies depending on the crowdedness of the platform; so that the negative effect of a highly emphasized pro-social orientation disappears when the platform is very crowded. This result and the related robustness checks suggest that, when the platform becomes more crowded, thus harshening the competition for attention, the pro-social orientation helps in demarcating a project from the others and has a beneficial effect. Therefore, when crowdedness increases, the positive effect of a limited pro-social orientation is 
enhanced and the negative effect of a high pro-social orientation fades away.

In this study, we make several contributions. First, we contribute to the literature on pro-social orientation. Research on the pursuit of pro-social goals has generally focused on specific sectors such as non-governmental and non-profit organizations. We know less about how the display of a pro-social orientation shapes the attainment of resources by entrepreneurs in for-profit contexts, where entrepreneurs serve multiple constituencies, and there is usually a need to balance the pro-social aspects with the personal self-interest of the funder (Battilana et al. 2015; Van de Ven et al. 2007). Our results contribute to addressing this gap. Overall, they indicate that pro-social framing does matter in reward-based crowdfunding, i.e., a context where pro-social aspects and selfinterest coexist. A positive effect of pro-social aims was found in a study on micro-lending, where the platform's main mission was to help projects pursuing pro-social goals, and emphasis on pro-social orientation drives the speed of resource acquisition (Moss et al. 2018). However, in contrast to this study, we find evidence of non-linear effects. Specifically, limited emphasis on prosocial orientation increases the chances of success, but too strong an emphasis on pro-social orientation reduces the chances of success. The negative effect of strong emphasis happens either when the pro-social cues are very frequent, or when they are placed in a prominent position in the hypertext, e.g., in the title or blurb.

Consistent with prior studies of ethical product consumption (Auger et al. 2008; Crane 2001) and in line with Van de Ven et al. (2007), we interpret these findings as suggesting that backers appreciate the pro-social orientation of a product, but only to the extent that this adds to-not replacesother features, such as product functionalities that increase the personal value and self-interest in the project. Furthermore, our results are in line with the argument suggesting that entrepreneurial projects that blend messages of prosocial logics and self-interest better reflect entrepreneurs' identity, and are perceived as more genuine, and therefore more credible, compared to messages that only stress the pro-social intentions of the entrepreneurs (Van de Ven et al. 2007; Fauchart and Gruber 2011). This is an important finding that, with some caution, could potentially be valid beyond the realm of crowdfunding.

Second, our results contribute to the discussion on the role of entrepreneurs' language and tone in mobilizing resources. In particular, our results show, consistently with those of Parhankangas and Elrich (2014), that the tone used to promote the project is important in securing funding, and that emphasis on positive language has a non-linear relationship with the success in mobilizing resources. Moreover, our study extends the work of Parhankangas and Elrich (2014) in two ways. First, it shows that the negative effects associated with overly positive language persist in contexts in which the funders are not professional investors. Second, it provides evidence that over-emphasizing has a negative effect on resource mobilization, when the emphasis is on pro-social goals; such effect was predicted, but not confirmed by the results of the study of Parhankangas and Elrich (2014). Moreover, our results are in line with the study of Meyer (1981) that suggest that consumers evaluate different product alternatives on the basis of both the information related to specific attributes and the absence of such information. Our results indicate that a high emphasis on pro-social motives in the context of crowdfunding cuts down information deemed important in this context, reducing the audience's interest in those projects. Consequently, we provide empirical evidence to the argument of Crane (2001) that in for-profit contexts, a product's pro-social attributes need to be a complement of functional ones, rather than representing the main attributes. In addition, our results show that besides a negative effect, over-emphasizing pro-social motives can also be useful when there is a need to demarcate a project over others and facilitate the screening of a large amount of information.

Third, we advance the literature and understanding of the determinants of success in crowdfunding. Our results provide a nuanced picture of how pro-social framing relates to crowdfunding project success and highlight the role of reward-based crowdfunding in making entrepreneurial finance more attentive to ethical stances. The expectation that direct engagement of citizens into entrepreneurial projects could make entrepreneurial finance more equitable, is yet to be backed by clear empirical evidence (Allison et al. 2015, 2017; Calic and Mosakowski 2016; Hörisch 2015). Moreover, we advance the debate on the determinants of crowdfunding project success by theoretically discussing and empirically documenting that how information is organized and displayed on crowdfunding platforms does matter. An issue that, to date, crowdfunding scholars have disregarded (Butticè et al. 2018).

Fourth, we contribute to the framing literature by analyzing the effect of framing in a digital context and highlighting the importance of framing emphasis in shaping frame effectiveness (Chong and Druckman 2007a, b; Hertog and McLeod 2001). By applying the lens of framing theory to a digital context, we highlight the role of information structure (in this case, a hierarchical structure) in favoring or hindering frame effectiveness. Furthermore, our results indicate that when a high number of projects compete for attention, the pro-social framing works to demarcate a project over others. Ultimately, 
such a "demarcating effect" would increase the visibility of a project, enhancing the likelihood of success. In particular, the results of robustness checks highlight that those projects that emphasize a pro-social orientation are the ones that are less penalized by a crowded environment. In other words, framing can mitigate the negative effect of competition. This finding contributes to the theory of framing by highlighting that the crowdedness of information plays a role in the appreciation of a framing. Overall, our results indicate that, in online contexts, the effectiveness of a pro-social framing is contingent on the emphasis, and the amount of information that competes for attention. Highlighting that the emphasis given to a frame (and where such an emphasis is positioned) matters for projects' success can also help reconciling some of the conflicting results found by prior empirical works in the context of reward-based platforms, which omitted to take into account the level of emphasis in the appreciation of a pro-social framing (e.g., Calic and Mosakowski 2016; Hörisch 2015).

Finally, we improve the methodology used to assess pro-social orientation in the crowdfunding context. Some crowdfunding studies equate projects' pro-social orientation to the presence of linguistic cues in the text (see Allison et al. 2015; Calic and Mosakowski 2016). In so doing, they measure pro-social orientation through a binary variable and thereby disregard the effect of the level of pro-social orientation, as well as the emphasis conveyed by position within the hypertext structure of web platform. These are, in our view, important shortcomings. Furthermore, our analysis uses a comprehensive definition of pro-social orientation. Conversely, prior studies have to date focused just on a subset of the possible aspects of this concept (i.e., sustainable, social, altruistic, environmental), leaving unexplored other important dimensions-such as fairness or equality - thereby depicting just a partial picture of the effect of pro-social orientation on project success. It is also worth noting that our analysis is based on more than 8000 projects, a sample that is much larger than those of extant studies. In conclusion, there are some interesting, and quite practical implications, for the ethically minded practitioner who aims at using crowding for the advancement of a common good.

As with any other study, this paper has limitations, which open up avenues for future research. First, it is worth acknowledging that our results are prone to alternative explanations. Our work finds that pro-social framing has nuanced effects on project success, which we attribute to the specific context of crowdfunding, and to the way information is displayed and organized. However, one may attribute our results to the fact that pro-social framing is a weak frame compared to other frames, which we do not specifically assess. Moreover, the results on the relationship between pro-social framing and crowdedness might indicate that framing per se is not relevant in information-rich contexts because an overwhelming amount of information might produce "noise" and cancel any effect of framing. This would be in line with the idea that framing might be less important than anticipated in crowded contexts as individuals are exposed to multiple frames. In such contexts, competing frames may cancel each other and fail to move public opinion (Chong and Druckman 2007a, p. 102; see also Brewer and Gross 2005).

Nevertheless, such an interpretation of the results would imply that the increase in the likelihood of success that we observe for projects displaying a high level of pro-social orientation when the level of crowdedness increases (Fig. 4) is due to a systematic error, i.e., individuals systematically selecting pro-social projects by mistake. We welcome studies that take into consideration these possible alternative explanations and back them with appropriate empirical testing. In particular, future studies should consider the effect of other frames, besides the pro-social one in reward-based contexts.

Second, our assumptions build on the idea that backers' appreciate multiple goals (e.g., entrepreneurs' selfinterest, economic goals, product functionalities) and success depends in part by the ability of entrepreneurs to communicate to a variegated audience with multiple opportunities, goals, and actions (Van de Ven et al. 2007; Weick et al. 2005). However, our methods do not allow us to observe the goals of the backers, leaving part of our assumptions untested. Future research should focus on backers' goals and unravel the relationship between success and fit between the project's goal framing and backers' behavior (Lindenberg and Steg 2007; Steg et al. 2014).

Third, we analyze the pro-social framing of crowdfunding projects at a given point in time, but the salience of a pro-social frame may change over time, depending on more general cultural attitudes; for instance, attention to environmental issues has indeed increased over time. Further studies should take into account this issue by using longitudinal data to measure how the level of pro-social orientation of crowdfunding projects, and its effect on project success, changes over time.

Fourth, we analyze the effect of the emphasis on prosocial orientation given by linguistic cues, but we omit to take into account the pro-social cues embedded in videos and images, in so doing we miss out the effect of paralinguistic cues. Tone, body language, gestures, facial expressions, are all examples of paralinguistic cues that can communicate emotions, attitudes and emphasize or downplay a framing (Meservy and Burgoon 2008). By 
omitting to consider videos and images, we are unable to capture the overall pro-social emphasis conveyed by the campaign combining linguistic with paralinguistic cues. Future studies could provide a more granular understanding of how pro-social cues are communicated by adding such elements to the analysis. For example, scholars could code static images conveying pro-social cues (see for example Benschop and Meihuizen 2002 for cues on gender embedded in report's images); furthermore, they could codify body language, voice tone, and acoustic cues displayed in videos (see Li, Y et al. 2015; $\mathrm{Li}$, JJ et al. 2017, for an analysis of paralinguistic cues in crowdfunding campaigns' videos), and assess their role in the relationship between pro-social orientation and success of the campaign. Finally, a textual analysis that includes the effect of the linguistic style could improve the assessment of how a pro-social emphasis is communicated within a text.

Fifth, our theoretical framework suggests that it is not possible to assess how a frame impacts individuals in digital markets without considering the whole process involved in the selection of a project that a platform enables. However, we do not directly observe how backers engage in the selection process of crowdfunding projects. For example, we use project descriptions as fundamental sources of information, and in so doing we overlook other potential sources of information, such as the bios of the proponents, the images and the video provided. This is a limitation of our study. We suggest that future works dig deeper into backers' process of search and selection and use alternative sources of information in order to improve our understanding of how crowdfunding support does occur.

Despite the aforementioned limitations, our work has interesting practical implications. First, the results indicate that project proponents should use pro-social orientation wisely. Conventional wisdom suggests that, in general, backers appreciate projects that go beyond proponents' pure self-interest. However, our results show that too much pro-social orientation may be detrimental. In sum, our findings show that a "too much of a good thing" effect can be at work in crowdfunding, and proponents should be aware of it when preparing the description of their projects. Second, our work should direct the attention of both projects' proponents and crowdfunding platform managers to the importance of how textual information about projects is organized for inducing crowd support. In particular, the title and blurb are fundamental for spotlighting projects in large, crowded platforms. Accordingly, managers of crowdfunding platforms that are not purposely built for the support of prosocial project should pay attention to these fundamental parts of the project description when they design the platform, and provide proponents with some indications on crafting the project's description to convey information effectively to the crowd.

Acknowledgements We thank Andrew Crane, Daniela Ceresa, Dimo Dimov, Simona Giorgi, Giancarlo Giudici, Massimiliano Guerini, Thomas Gegenhuber, Davide Hahn, Christos Kolympiris, Ammon Salter, Ahmed Sewaid, Paul F. Skilton, Francesca Tenca, and participants of the 35th Egos subtheme Digitalization of Work and Organizations, 2018 EntFin Conference, 2018 R\&D Management Conference, 2017 Babson Conference, for their helpful comments. We are grateful to Stephan Hielscher for his help in validating the list of words used in the empirical analysis. We also thank platform founders and managers Cindy Wu e Danny Luan (experiment.com), Angelo Rindone (Produzioni dal Basso and Folkfunding), and Claudio Bedino (Oval Money and Starteed) for their useful insights on crowdfunding platforms. We are indebted to three anonymous reviewers and the section editor for their valuable comments and guidance.

\section{Compliance with Ethical Standards}

Conflicts of interest The authors declare that they have no conflict of interest.

Research Involving Human Participants and/or Animals This article does not contain any studies with human participants or animals performed by any of the authors.

Informed Consent This study rely exclusively on information publicly available on Kickstarter platform and adheres to the term of use defined by Kickstarter (https://www.kickstarter.com/terms-of-use). Specifically, Kickstarter allows the use of information posted on his platform for non-commercial use.

Open Access This article is licensed under a Creative Commons Attribution 4.0 International License, which permits use, sharing, adaptation, distribution and reproduction in any medium or format, as long as you give appropriate credit to the original author(s) and the source, provide a link to the Creative Commons licence, and indicate if changes were made. The images or other third party material in this article are included in the article's Creative Commons licence, unless indicated otherwise in a credit line to the material. If material is not included in the article's Creative Commons licence and your intended use is not permitted by statutory regulation or exceeds the permitted use, you will need to obtain permission directly from the copyright holder. To view a copy of this licence, visit http://creativecommons.org/licenses/by/4.0/.

\section{Appendix}

See Figs. 5 and 6. 


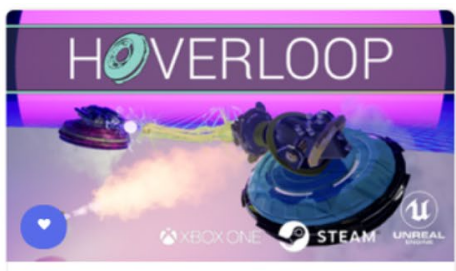

Hoverloop Not A Company

Splitscreen PC/Console Arcade Arena Combat game. Fight eachother with customizable drones in an array of game modes.

\begin{tabular}{l} 
P Peer, Belgium \\
\hline $\mathbf{9 1 \%} \quad \mathbf{\epsilon 1 3 , 7 2 8}$ \\
funded pledged
\end{tabular}

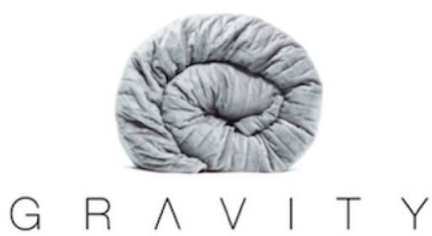

Gravity: The Weighted Blanket for Sleep, Stress and Anxiety

John Fiorentino

A weighted blanket engineered to be $10 \%$ of your body weight to naturally reduce stress and increase relaxation.

Q Brooklyn, NY

$14536 \% \$ 3,125,325$

funded pledged

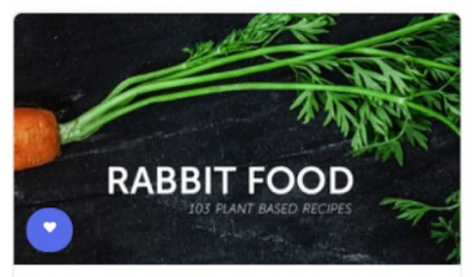

Rabbit Food - A Plant Based Cookbook by Gianna Ciaramello

Gianna Ciaramello

A Plant-Based cookbook featuring 103 original recipes from myself and 4 other influential foodies!

? Morristown, NJ

\section{$\mathbf{9 7 \%} \quad \$ 4,880$}

funded pledged

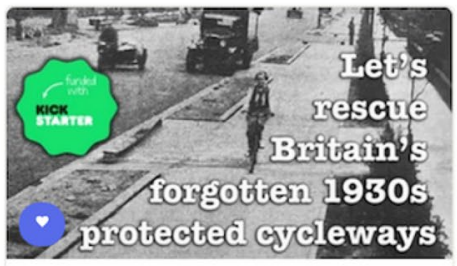

Let's rescue Britain's forgotten 1930s protected cycleways

Carlton Reid

We should revive Britain's long-lost 1930s cycleways (there were 280-miles of them). Many were buried. some are hidden in plain sight.

- Newcastle upon Tyne, UK

\section{$224 \% \quad £ 15,746$}

funded pledged

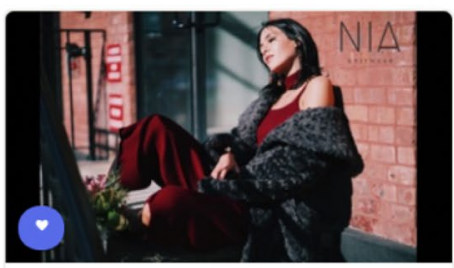

NIA | Eco-Friendly Knitwear for an Unpredictable Life.

Merica Kahn

NIA is Eco-friendly knitwear developed on

WHOLEGARMENT@ 3D knitting machines, which

means no seams for your comfort! Made in the USA!

P Jersey City, N.

$80 \% \quad \$ 9,680$

funded pledged

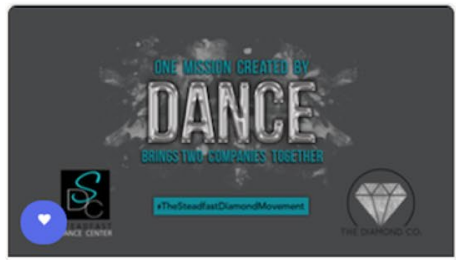

The Steadfast Diamond Movement

Sarah A. Lozano | Jasper C. Reed

Two dance companies come together on a mission to

find a studio space to call home. Where possibilities become reality.

Chicago, IL

$110 \% \$ 11,015$

funded pledged

Fig. 5 Example of mosaic display. The illustration shows the list of open projects displayed in Kickstarter's main webpage on May 11, 2017. Note that the project at the top right has pro-social cues in title and blurb

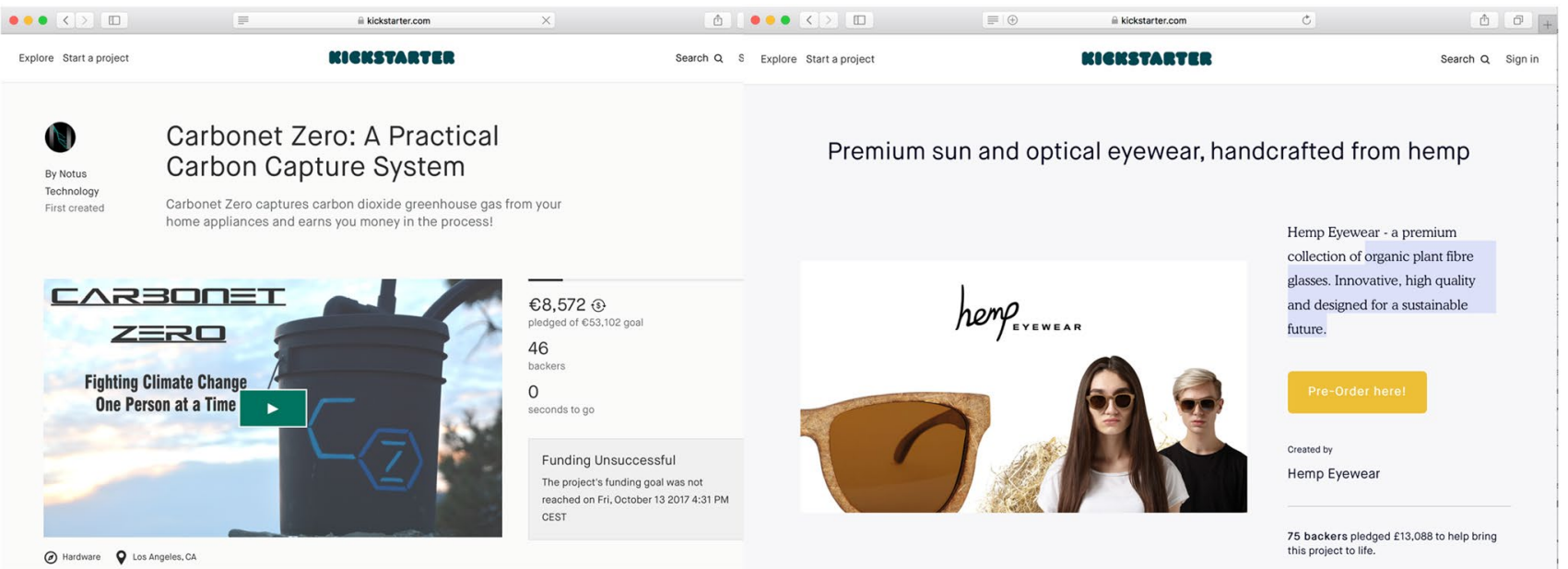

Fig. 6 Example of project with pro-social framing. The illustration shows two screenshots of projects in which the pro-social framing is visible from the title and blurb 


\section{References}

Allison, T. H., Davis, B. C., Short, J. C., \& Webb, J. W. (2015). Crowdfunding in a prosocial microlending environment: Examining the role of intrinsic versus extrinsic cues. Entrepreneurship: Theory and Practice, 39(1), 53-73. https://doi.org/10.1111/etap.12108.

Allison, T. H., Davis, B. C., Webb, J. W., \& Short, J. C. (2017). Persuasion in crowdfunding: An elaboration likelihood model of crowdfunding performance. Journal of Business Venturing, 32(6), 707-725. https://doi.org/10.1016/j.jbusvent.2017.09.002.

André, K., Bureau, S., Gautier, A., \& Rubel, O. (2017). Beyond the opposition between altruism and self-interest: Reciprocal giving in reward-based crowdfunding. Journal of Business Ethics, 146(2), 313-332. https://doi.org/10.1007/s10551-017-3652-x.

Auger, P., Devinney, T. M., Louviere, J. J., \& Burke, P. F. (2008). Do social product features have value to consumers? International Journal of Research in Marketing, 25(3), 183-191. https://doi. org/10.1016/j.ijresmar.2008.03.005.

Austin, J., Stevenson, H., \& Wei-Skillern, J. (2006). Social and commercial entrepreneurship: Same, different, or both? Entrepreneurship Theory and Practice, 30(1), 1-22. https://doi.org/10.11 11/j.1540-6520.2006.00107.x.

Battilana, J., Sengul, M., Pache, A.-C., \& Model, J. (2015). Harnessing productive tensions in hybrid organizations: The case of working integration social enterprises. Academy of Management Journal, 58(6), 1658-1685. https://doi.org/10.5465/amj.2013.0903.

Benford, R. D., \& Snow, D. A. (2000). Framing processes and social movements: An overview and assessment. Annual Review of Sociology. https://doi.org/10.2307/223459.

Benschop, Y., \& Meihuizen, H. E. (2002). Keeping up gendered appearances: Representations of gender in financial annual reports. Accounting, Organizations and Society, 27(7), 611-636. https://doi.org/10.1016/S0361-3682(01)00049-6.

Bettman, J. R., Luce, M. F., \& Payne, J. W. (1998). Constructive consumer choice processes. Journal of Consumer Research, 25(3), 187-217. https://doi.org/10.1086/209535.

Bhattacharya, C. B., Korschun, D., \& Sen, S. (2009). Strengthening stakeholder-company relationships through mutually beneficial corporate social responsibility initiatives. Journal of Business Ethics, 85(SUPPL. 2), 257-272. https://doi.org/10.1007/s1055 1-008-9730-3.

Brewer, P. R., \& Gross, K. (2005). Values, framing, and citizens' thoughts about policy issues: Effects on content and quantity. Political Psychology, 26(6), 929-948. https://doi.org/10.111 1/j.1467-9221.2005.00451.x.

Brickson, S. L. (2007). Organizational identity orientation: The genesis of the role of the firm and distinct forms of social value. The Academy of Management Review, 32(3), 864-888. https://doi. org/10.2307/20159339.

Broniarczyk, S. M., \& Griffin, J. G. (2014). Decision difficulty in the age of consumer empowerment. Journal of Consumer Psychology, 24(4), 608-625. https://doi.org/10.1016/J.JCPS.2014.05.003.

Burke, K. (1984). Attitudes toward history. California: University of California Press.

Butticé, V., Franzoni, C., Rossi-Lamastra, C., \& Rovelli, P. (2018). The road to crowdfunding success: A review of the extant literature. In A. Afuah, C. Tucci, \& G. Viscusi (Eds.), Creating and capturing value through crowdsourcing (pp. 97-123). Kettering: Oxford University Press. https://doi.org/10.1093/oso/9780198816 225.003.0005.

Calic, G., \& Mosakowski, E. (2016). Kicking off social entrepreneurship: How a sustainability orientation influences crowdfunding success. Journal of Management Studies, 53(5), 738-767. https ://doi.org/10.1111/joms.12201
Cholakova, M., \& Clarysse, B. (2015). Does the possibility to make equity investments in crowdfunding projects crowd out rewardbased investments? Entrepreneurship Theory and Practice, 39(1), 145-172. https://doi.org/10.1111/etap.12139.

Chong, D., \& Druckman, J. N. (2007a). A theory of framing and opinion formation in competitive elite environments. Journal of Communication, 57(1), 99-118. https://doi.org/10.111 1/j.1460-2466.2006.00331.x.

Chong, D., \& Druckman, J. N. (2007b). Framing theory. Annual Review of Political Science, 10(1), 103-126. https://doi.org/10.1146/annur ev.polisci.10.072805.103054.

Colombo, M. G., Franzoni, C., \& Rossi-Lamastra, C. (2015). Internal social capital and the attraction of early contributions in crowdfunding. Entrepreneurship Theory and Practice, 39(1), 75-100. https://doi.org/10.1111/etap.12118.

Cornelissen, J. P., \& Werner, M. D. (2014). Putting framing in perspective: A review of framing and frame analysis across the management and organizational literature. Academy of Management Annals, 8(1), 181-235. https://doi.org/10.1080/19416 520.2014 .875669$.

Crane, A. (2001). Unpacking the ethical product. Journal of Business Ethics, 30(4), 361-373. https://doi.org/10.1023/A:1010793013 027.

Drover, W., Wood, M. S., \& Fassin, Y. (2014). Take the money or run ? Investors' ethical reputation and entrepreneurs' willingness to partner. Journal of Business Venturing, 29(6), 723-740. https:// doi.org/10.1016/j.jbusvent.2013.08.004.

Druckman, J. N., Lynn Hennessy, C., St Charles, K., \& Webber, J. (2010). Competing rhetoric over time: Frames versus cues. The Journal of Politics, 72(1), 136-148. https://doi.org/10.1017/s0022 381609990521.

Eckhardt, G. M., Belk, R., \& Devinney, T. M. (2010). Why don't consumers consume ethically? Journal of Consumer Behaviour, 9(6), 426-436. https://doi.org/10.1002/cb.332.

Fassin, Y., \& Drover, W. (2017). Ethics in entrepreneurial finance: Exploring problems in venture partner entry and exit. Journal of Business Ethics, 140(4), 649-672. https://doi.org/10.1007/s1055 1-015-2873-0.

Fauchart, E., \& Gruber, M. (2011). Darwinians, communitarians, and missionaries: The Role of founder identity in entrepreneurship. Academy of Management Journal, 54(5), 935-957. https://doi. org/10.5465/amj.2009.0211.

Fiss, P. C., \& Hirsch, P. M. (2005). The discourse of globalization: Framing a and sensemaking of an emerging concept. American Sociological Review, 70(2), 29-52. https://doi.org/10.1177/00031 2240507000103.

Giorgi, S., \& Weber, K. (2015). Marks of distinction. Administrative Science Quarterly, 60(2), 333-367. https://doi.org/10.1177/00018 39215571125.

Goffman, E. (1974). Frame analysis: An essay on the organization of experience. Cambridge, MA: Harvard University Press.

Hansen, M. T., \& Haas, M. (2001). Competing for attention in knowledge markets: Electronic document dissemination in a management consulting company. Administrative Science Quarterly, $46(1), 1-28$

Hemer, J. (2011). A snapshot on crowdfunding. Enconstor. https://doi. org/10.1227/01.NEU.0000349921.14519.2A.

Hertog, J. K., \& McLeod, D. M. (2001). A multiperspectival approach to framing analysis: A field guide. In S. D. Reese, O. H. Gandy, \& A. E. Grant (Eds.), Framing public life: Perspectives of media and our understanding of the social world (pp. 139-161). New York: Routledge. https://doi.org/10.4324/9781410605689.

Hörisch, J. (2015). Crowdfunding for environmental ventures: An empirical analysis of the influence of environmental orientation on the success of crowdfunding initiatives. Journal of Cleaner 
Production, 107, 636-645. https://doi.org/10.1016/J.JCLEP RO.2015.05.046.

Ioannou, I., \& Serafeim, G. (2015). The impact of corporate social responsibility on investment recommendations: Analysts' perceptions and shifting institutional logics. Strategic Management Journal, 36(7), 1053-1081. https://doi.org/10.1002/smj.2268.

Johnson, T. C. (2015). Reciprocity as a foundation of financial economics. Journal of Business Ethics, 131(1), 43-67. https://doi. org/10.1007/s10551-014-2257-x.

Kim, P. H., Buffart, M., \& Croidieu, G. (2016). TMI: Signaling credible claims in crowdfunding campaign narratives. Group and Organization Management, 41(6), 717-750. https://doi. org/10.1177/1059601116651181.

Kivetz, R., Simonson, I., Ran, K., \& Itamar, S. (2000). The effects of incomplete information on consumer choice. Journal of Marketing Research, 37(4), 427-448. https://doi.org/10.1509/ jmkr.37.4.427.18796.

Krippendorff, K. (2004). Reliability in content analysis. Human Communication Research, 30(3), 411-433. https://doi. org/10.1111/j.1468-2958.2004.tb00738.x.

Kulviwat, S., Guo, C. Q., \& Engchanil, N. (2004). Determinants of online information search: A critical review and assessment. Internet Research-Electronic Networking Applications and Policy, 14(3), 245-253. https://doi.org/10.1108/1066240410 542670.

Kuppuswamy, V., \& Bayus, B. L. (2017). Does my contribution to your crowdfunding project matter? Journal of Business Venturing. https://doi.org/10.1016/j.jbusvent.2016.10.004.

Laver, M., \& Garry, J. (2000). Estimating policy positions from political texts. American Journal of Political Science, 44(3), 619-634. https://doi.org/10.2307/2669268.

Levin, I. P., Schneider, S. L., \& Gaeth, G. J. (1998). All frames are not created equal: A typology and critical analysis of framing effects. Organizational Behavior and Human Decision Processes, 76(2), 149-188. https://doi.org/10.1006/ obhd.1998.2804.

Li, J. J., Chen, X. P., Kotha, S., \& Fisher, G. (2017). Catching fire and spreading it: A glimpse into displayed entrepreneurial passion in crowdfunding campaigns. Journal of Applied Psychology, 102(7), 1075-1090. https://doi.org/10.1037/apl0000217.

Li, Y., Wu, S., Xiao, N., \& Redd, T. (2015). Smile: Click! Here is your money! The effect of non-verbal cues on crowdfunding success. Academy of Management Proceedings, 2015(1), 12914. https:// doi.org/10.5465/ambpp.2015.12914abstract.

Lindenberg, S., \& Steg, L. (2007). Normative, gain and hedonic goal frames guiding environmental behavior. Journal of Social Issues, 63(1), 117-137. https://doi.org/10.1111/j.1540-4560.2007.00499 .x.

Lurie, N. H. (2004). Decision making in information-rich environments: The role of information structure. Journal of Consumer Research, 30(4), 473-486. https://doi.org/10.1086/380283.

March, J. G., \& Simon, H. A. (1958). Organizations. New York: Wiley.

Marin, L., \& Ruiz, S. (2007). "I need you too!" Corporate identity attractiveness for consumers and the role of social responsibility. Journal of Business Ethics, 71(3), 245-260. https://doi. org/10.2307/25075331.

McKenny, A. F., Aguinis, H., Short, J. C., \& Anglin, A. H. (2016). What doesn't get measured does exist: Improving the accuracy of computer-aided text analysis. Journal of Management, 44(7), 2909-2933. https://doi.org/10.1177/0149206316657594.

McKnight, C., Dillon, A., \& Richardson, J. (1991). Hypertext in context (Vol. 6). Cambridge: Cambridge University Press. https://doi. org/10.1016/0020-7373(92)90062-p.
Meservy, T. O., \& Burgoon, J. K. (2008). Paralanguage. In W. Donsbach (Eds.) The International Encyclopedia of Communication. Malden: Blackwell Pub.

Meyer, R. J. (1981). A Model of multiattribute judgments under attribute uncertainty and informational constraint. Journal of Marketing Research, 18(4), 428. https://doi.org/10.2307/3151336.

Mollick, E. (2014). The dynamics of crowdfunding: An exploratory study. Journal of Business Venturing, 29(1), 1-16. https://doi. org/10.1016/j.jbusvent.2013.06.005.

Moss, T. W., Renko, M., Block, E., \& Meyskens, M. (2018). Funding the story of hybrid ventures: Crowdfunder lending preferences and linguistic hybridity. Journal of Business Venturing, 33(5), 643-659. https://doi.org/10.1016/j.jbusvent.2017.12.004.

Nilsson, J. (2008). Investment with a conscience: Examining the impact of pro-social attitudes and perceived financial performance on socially responsible investment behavior. Journal of Business Ethics, 83(2), 307-325. https://doi.org/10.1007/s10551-007-9621-z.

Ocasio, W. (2011). Attention to attention. Organization Science, 22(5), 1286-1296. https://doi.org/10.1287/orsc.1100.0602.

Olsen, M. C., Slotegraaf, R. J., \& Chandukala, S. R. (2014). Green claims and message frames: How green new products change brand attitude. Journal of Marketing, 78(5), 119-137. https://doi. org/10.1509/jm.13.0387.

Parhankangas, A., \& Ehrlich, M. (2014). How entrepreneurs seduce business angels: An impression management approach. Journal of Business Venturing, 29(4), 543-564. https://doi.org/10.1016/j. jbusvent.2013.08.001.

Payne, J. W., Bettman, J. R., \& Johnson, E. J. (1993). The adaptive decision maker. Cambridge: Cambridge University Press.

Reinhardt, F. L. (1998). Environmental product differentiation: implications for corporate strategy. California Management Review, 40(4), 43-73.

Rhee, E. Y., \& Fiss, P. C. (2014). Framing controversial actions: Regulatory focus, source credibility, and stock market reaction to poison pill adoption. Academy of Management Journal, 57(6), 1734-1758. https://doi.org/10.5465/amj.2012.0686.

Rodale, J. (1978). The synonym finder. Gordonsville: Rodale Books.

Rodgers, W., Choy, H. L., \& Guiral, A. (2013). Do investors value a firm's commitment to social activities? Journal of Business Ethics, 114(4), 607-623. https://doi.org/10.1007/s10551-013-1707-1.

Secchi, D. (2009). The cognitive side of social responsibility. Journal of Business Ethics, 88(3), 565-581. https://doi.org/10.1007/s1055 1-009-0124-y.

Sen, S., \& Bhattacharya, C. B. (2001). Does doing good always lead to doing better? Consumer reactions to corporate social responsibility. Journal of Marketing Research, 38(2), 225-243. https://doi. org/10.1509/jmkr.38.2.225.18838.

Shen, F. (2004). Effects of news frames and schemas on individuals' issue interpretations and attitudes. Journalism \& Mass Communication Quarterly, 81(2), 400-416. https://doi.org/10.1177/10776 9900408100211.

Shepherd, D. A., Mcmullen, J. S., \& Ocasio, W. (2017). Is that an opportunity? An attention model of top managers' opportunity beliefs for strategic action. Strategic Management Journal, 38(3), 626-644. https://doi.org/10.1002/smj.2499.

Short, J. C., Ketchen, D. J., Shook, C. L., \& Ireland, R. D. (2010). The concept of "opportunity" in entrepreneurship research: Past accomplishments and future challenges. Journal of Management, 36(1), 40-65. https://doi.org/10.1177/0149206309342746.

Simon, H. A. (1986). The role of attention in cognition. New York: Academic Press.

Steg, L., Bolderdijk, J. W., Keizer, K., \& Perlaviciute, G. (2014). An integrated framework for encouraging pro-environmental behaviour: The role of values, situational factors and goals. 
Journal of Environmental Psychology, 38, 104-115. https://doi. org/10.1016/j.jenvp.2014.01.002.

Van de Ven, A. H., Sapienza, H. J., \& Villanueva, J. (2007). Entrepreneurial pursuits of self- and collective interests. Strategic Entrepreneurship Journal, 1(3-4), 353-370. https://doi.org/10.1002/ sej.34.

Weick, K. E., Sutcliffe, K. M., \& Obstfeld, D. (2005). Organizing and the process of sensemaking. Organization Science, 16(4), 409421. https://doi.org/10.1287/orsc.1050.0133.

Zhang, H., \& Hoosain, R. (2001). The influence of narrative text characteristics on thematic inference during reading. Journal of Research in Reading, 24(2), 173-186. https://doi. org/10.1111/1467-9817.00140.
Zhang, H., \& Salvendy, G. (2001). The implications of visualization ability and structure preview design for web information search tasks. International Journal of Human-Computer Interaction, 13(1), 75-95. https://doi.org/10.1207/S15327590IJHC1301_5.

Publisher's Note Springer Nature remains neutral with regard to jurisdictional claims in published maps and institutional affiliations. 